\title{
A review of reviews on principles, strategies, outcomes and impacts of research partnerships approaches: a first step in synthesising the research partnership literature
}

\author{
F. Hoekstra ${ }^{1,2}$ (D) K. J. Mrklas ${ }^{3,4}$, M. Khan ${ }^{5}$, R. C. McKay ${ }^{1,2}$, M. Vis-Dunbar ${ }^{6}$, K. M. Sibley ${ }^{5,7}$, T. Nguyen $^{8,9}$, \\ I. D. Graham ${ }^{10,11}$, SCl Guiding Principles Consensus Panel and H. L. Gainforth ${ }^{1,2^{*}}$
}

\begin{abstract}
Background: Conducting research in partnership with stakeholders (e.g. policy-makers, practitioners, organisations, patients) is a promising and popular approach to improving the implementation of research findings in policy and practice. This study aimed to identify the principles, strategies, outcomes and impacts reported in different types of reviews of research partnerships in order to obtain a better understanding of the scope of the research partnership literature.

Methods: This review of reviews is part of a Coordinated Multicenter Team approach to synthesise the research partnership literature with five conceptually linked literature reviews. The main research question was What principles, strategies, outcomes and impacts are reported in different types of research partnership approaches?'. We included articles describing a literature review of research partnerships using a systematic search strategy. We used an adapted version of the Revised Assessment of Multiple Systematic Reviews tool to assess quality. Nine electronic databases were searched from inception to April 2018. Principles, strategies, outcomes and impacts were extracted from the included reviews and analysed using direct content analysis.

Results: We included 86 reviews using terms describing several research partnership approaches (e.g. community-based participatory research, participatory research, integrated knowledge translation). After the analyses, we synthesised 17 overarching principles and 11 overarching strategies and grouped them into one of the following subcategories: relationship between partners; co-production of knowledge; meaningful stakeholder engagement; capacity-building, support and resources; communication process; and ethical issues related to the collaborative research activities. Similarly, we synthesised 20 overarching outcomes and impacts on researchers, stakeholders, the community or society, and the research process.

(Continued on next page)
\end{abstract}

\footnotetext{
*Correspondence: heather.gainforth@ubc.ca

'School of Health \& Exercise Sciences, University of British Columbia, Kelowna, Canada

${ }^{2}$ International Collaboration on Repair Discoveries (ICORD), University of British Columbia, Vancouver, Canada

Full list of author information is available at the end of the article
}

\section{$\triangle B M C$}

(c) The Author(s). 2020 Open Access This article is licensed under a Creative Commons Attribution 4.0 International License, which permits use, sharing, adaptation, distribution and reproduction in any medium or format, as long as you give appropriate credit to the original author(s) and the source, provide a link to the Creative Commons licence, and indicate if changes were made. The images or other third party material in this article are included in the article's Creative Commons licence, unless indicated otherwise in a credit line to the material. If material is not included in the article's Creative Commons licence and your intended use is not permitted by statutory regulation or exceeds the permitted use, you will need to obtain permission directly from the copyright holder. To view a copy of this licence, visit http://creativecommons.org/licenses/by/4.0/ The Creative Commons Public Domain Dedication waiver (http://creativecommons.org/publicdomain/zero/1.0/) applies to the data made available in this article, unless otherwise stated in a credit line to the data. 
(Continued from previous page)

Conclusions: This review of reviews is the first that presents overarching principles, strategies, outcomes and impacts of research partnerships. This review is unique in scope as we synthesised literature across multiple research areas, involving different stakeholder groups. Our findings can be used as a first step to guide the initiation and maintenance of research partnerships and to create a classification system of the key domains of research partnerships, which may improve reporting consistency in the research partnership literature.

Trial registration: This study is registered via Open Science Framework: https://doi.org/10.17605/OSF.IO/GVR7Y.

Keywords: Collaborative research partnerships, Integrated knowledge translation, Community-based participatory research, Stakeholder engagement, Research principles and strategies, Research outcomes and impact, Knowledge syntheses

\section{Background}

Increasingly, research partnerships in which researchers and stakeholders work together on a research project are becoming a widely accepted, and sometimes mandated, approach to implementation [1-5]. These partnerships aim to shift the research paradigm from one in which the researcher is the sole expert to one in which researchers and stakeholders co-lead research activities and collectively apply their expertise, knowledge and skills within a team [6]. While these research partnerships are a broadly accepted tenet of knowledge translation [7], there is limited literature describing the optimal processes (i.e. principles, strategies) for research coproduction and limited empirical evidence supporting the perceived outcomes or impacts of working in partnership.

The variability in research partnership approaches and terminologies (e.g. community-based participatory research (CBPR), participatory action research (PAR), integrated knowledge translation (IKT)) across multiple research fields present substantial challenges for syntheses in the field of research partnerships, including complexities arising from diverse definitions, conceptual similarities/differences, evidence volume and dispersion, logistics/resource and feasibility issues [1, 8-10]. Syntheses of various partnership approaches from different research fields are needed to develop an understanding of the literature, learn from others' successes and challenges, and to advance the science of research partnerships and implementation [11]. To address these challenges, our team developed a collaborative review approach (i.e. Coordinated Multicenter Team) to reviewing and synthesising research partnership literature [11]. This standardised approach is described elsewhere [11] and aims to conduct five conceptually linked literature reviews focusing on research partnerships. To address the gaps in the research partnership literature $[7,8]$, the approach is guided by a consensus-driven conceptual framework and is focused on four key domains of research partnership - principles, strategies, outcomes and impacts. Additional file 1: Appendix 1 presents the framework and related definitions.
This review presents findings from the first step in our Coordinated Multicenter Team approach - a review of reviews on key domains of research partnerships. In accordance with our conceptual framework, this review of reviews identifies the principles, strategies, outcomes and impacts reported in different types of research partnership approaches in order to gain a better understanding of the scope of the research partnership literature. In particular, this review (1) provides an overview of terms, definitions and descriptions used in the research partnership literature, and (2) synthesises overarching principles, strategies, outcomes and impacts of research partnership approaches.

As the review of reviews primarily aimed to guide our next steps in synthesising the research partnership literature (i.e. scoping reviews and umbrella reviews), this review of reviews did not aim to provide a comprehensive overview of the research partnership literature.

\section{Methods}

\section{Study protocol and registration}

This paper describes a review of reviews focusing on four key domains of research partnerships - principles, strategies, outcomes and impacts (Additional file 1: Appendix 1). The study was guided by the Preferred Reporting Items for Systematic Reviews and Meta-Analyses (PRISMA) [12] and by Pollock et al. [13] for the conduct of overviews of reviews. Additional file 1: Appendix 2 presents details about adherence to the PRISMA guidelines. The published protocol [11] was registered in Open Science Framework (OSF) $[14,15]$. Protocol deviations are reported on OSF [16].

\section{Search strategy and eligibility criteria}

The following data sources were searched by academic librarians (MVD, CN): Medline, Embase, CINAHL, PsycINFO, Eric, Education Source, Social Services Abstracts, Sociological Abstracts, Sociology Database, Applied Social Sciences Index and Abstracts, Web of Science Core Collection and JSTOR. The health databases (Medline, Embase, CINAHL, PsycInfo) were searched from inception to January 2018 and updated in April 2018. The other 
databases were searched from inception to April 2018. The search strategy identified reviews on the following concepts: partnership research, participatory research, knowledge translation and knowledge transfer. As we did not aim to provide a comprehensive overview of the research partnership literature, we opted for a high-level search strategy to capture global terms related to partnership, participatory and community-focused research. Our working hypothesis was that key reviews on research partnership approaches would use standardised, aggregated expressions and terminology to describe the research processes being reviewed [11]. As described in our protocol paper [11], the findings from this review were to be used to develop a more comprehensive search strategy for our subsequent scoping reviews that leverages both standardised terms across disciplines as well as natural language expressions of partnership research. In collaboration with academic librarians (MVD, CJN), we decided to start our collaborative review process (i.e. this review of reviews) with a high level search strategy and subsequently develop a refined and more comprehensive search strategy for our scoping reviews aligned with our general collaborative focus on maximising search strategy efficiencies and optimising research quality [11].

Final search strategies for each database are available on OSF (OSF - Table I). In addition to the database search, reference lists of included reviews were scanned to identify relevant reviews.

We included reviews that described a literature review on how research partnerships work (i.e. principles or strategies) or described the outcomes or impacts of research partnerships. Table 1 presents the inclusion and exclusion criteria.

\section{Engagement of stakeholders in the review}

A steering committee, consisting of a group of stakeholders interested in developing guiding principles for conducting and disseminating research in partnership with people with spinal cord injury (SCI), was established (the SCI Guiding Principles Consensus Panel). The panel members' names, organisations and roles are described in Additional file 1: Appendix 3, including people with lived experience of SCI, decision-makers, healthcare professionals, representatives from community organisations

Table 1 Inclusion and exclusion criteria

\begin{tabular}{|c|c|c|}
\hline Topic & Inclusion criteria & Exclusion criteria \\
\hline Scope & $\begin{array}{l}\text { - The aim/objective/purpose/research question of the literature } \\
\text { review should focus (partly) on research partnership (e.g. } \\
\text { how partnerships work; what are the outcomes or impacts) } \\
\text { - The paper describes a literature review on how research } \\
\text { partnerships work (i.e. principles or strategies) OR the paper } \\
\text { describes a literature review on outcomes or impacts of } \\
\text { research partnerships } \\
\text { - The literature review included studies that described or } \\
\text { evaluated the research partnership OR described or } \\
\text { evaluated the collaborative research activity OR described } \\
\text { or evaluated methods or tools to study partnerships or } \\
\text { collaborative research activity }\end{array}$ & $\begin{array}{l}\text { - The paper used/applied a research partnership approach } \\
\text { without studying it } \\
\text { - The paper concluded that research partnerships are } \\
\text { relevant/useful without studying it } \\
\text { - The paper describes a literature review on knowledge } \\
\text { translation and/or knowledge mobilisation without a } \\
\text { focus on research partnership } \\
\text { - The paper does not include any extractable data related } \\
\text { to principles, strategies, outcomes or impacts }\end{array}$ \\
\hline Definition & $\begin{array}{l}\text { - The paper meets our definition of research partnership: } \\
\text { o Research partnership is defined as "individuals, groups } \\
\text { or organisations engaged in collaborative research activity } \\
\text { involving at least one researcher (e.g., individual affiliated } \\
\text { with an academic institution), and any stakeholder (e.g., } \\
\text { decision or policy-maker, healthcare administrator or leader, } \\
\text { community agency, charities, network, patients etc.)" [2, 11] } \\
\text { - The paper includes a definition or description of the } \\
\text { research partnership approach }\end{array}$ & $\begin{array}{l}\text { - The paper does not meet our definition of research } \\
\text { partnership. Examples include: } \\
\text { ॰A researcher is not part of the partnership (e.g. } \\
\text { physician-patient partnership; student-teacher } \\
\text { partnership) } \\
\text { ○A stakeholder is not part of the partnership (e.g. } \\
\text { partnership between researchers from different } \\
\text { disciplines or different countries) } \\
\text { - The paper focused on public-private partnerships } \\
\text { or university-industry partnerships } \\
\text { - The paper does not describe or define the research } \\
\text { partnership approach }\end{array}$ \\
\hline $\begin{array}{l}\text { Design and search } \\
\text { strategy }\end{array}$ & $\begin{array}{l}\text { - The paper describes a literature overview of research } \\
\text { partnerships } \\
\text { - The paper used a systematic search } \\
\text { (provided a general description of their search strategy } \\
\text { in terms of their search terms, eligibility criteria and } \\
\text { databases that are searched) of the literature }\end{array}$ & $\begin{array}{l}\text { - The paper describes a review of a method or tool } \\
\text { instead of a literature overview } \\
\text { - The paper combined the literature study with another } \\
\text { study design (e.g. case study) without making a distinction } \\
\text { between the results derived from the literature review } \\
\text { and the other data source } \\
\text { - The paper searched only grey literature; the paper did } \\
\text { not search electronic databases (e.g. ERIC, Medline, } \\
\text { Psyclnfo) }\end{array}$ \\
\hline Language & - The paper is published in English language & - The paper is not published in English language \\
\hline
\end{tabular}

Notes: Additional file 1: Appendix 1 presents our guiding framework and related key definitions of the research partnership domains (principles, strategies, outcomes, impacts) 
and researchers. For this review of reviews, members were engaged in three key research activities, namely (1) conceptual design and formulation of the research questions; (2) preparation of data extraction forms; and (3) data analysis, interpretation and dissemination of results.

Additional file 1: Appendix 4 provides an overview of our participatory (IKT) approach, including the collaborative research activities, associated dates, topics discussed, stakeholders' concerns and suggestions, and our responses.

\section{Screening process}

Search results were exported to Endnote X.7.5.3 and deduplication was conducted following the steps described by Bramer et al. [17]. The results were exported, managed and analysed using a combination of Rayyan [18] and Excel.

The screening process was executed in three phases title, abstract and full text. First, titles of all citations were independently screened by at least two team members (FH, KJM, MK). Only citations excluded by two team members were excluded in this screening phase. Second, title and abstracts were independently screened by two team members ( $\mathrm{FH}$ and $\mathrm{KJM}, \mathrm{FH}$ and $\mathrm{MK}, \mathrm{FH}$ and RM) using the abstract-level eligibility criteria. Reliability between each pair of screeners (FH and KJM, FH and MK, FH and RM) was calculated using Cohen's Kappa statistic during this and full text screening [19]. All discrepancies between coders were discussed and resolved through a consensus discussion. Third, full-texts were screened independently by two team members (FH and $\mathrm{MK}, \mathrm{FH}$ and $\mathrm{RM}$ ) using inclusion criteria described in Table 1. Discrepancies between coders were discussed and resolved. If necessary, a third team member (MK or RM) was contacted for a final decision.

\section{Data extraction and analyses}

The first author (FH) and research assistants (PS, DS, $\mathrm{KW})$ extracted general review characteristics and partnership characteristics using an online data extraction form. Review characteristics were extracted, including the year of publication, country of first author, title, study aims, research area, research population and type of literature review. Extracted partnership characteristics included key terms used to describe the research partnership approach (e.g. CBPR, PAR, IKT), definition or description of the research partnership, and partnerships' members. After data extraction, one researcher $(\mathrm{FH})$ organised the information related to the research area and research population. The findings were then discussed and refined during a meeting with other researchers (KJM, MK, KS, TN, HG). Key characteristics of each review were exported to an Excel sheet and published on OSF - Table III.
Two researchers worked together to extract the data related to the key domains (principles/strategies: $\mathrm{FH}$ and RM; outcomes/impacts: $\mathrm{FH}$ and $\mathrm{MK}$ ) using definitions described in Additional file 1: Appendix 1. We used an iterative extraction and analysis process, guided by direct content analysis [20], consisting of the following steps:

- Development of coding manual. We developed three coding manuals (principles, strategies, outcomes/ impacts) using the extracted information of 8 randomly selected reviews $(\sim 10 \%)$. In contrast to our protocol, a single coding manual was created by combining outcomes and impacts. A combined manual was deemed a better fit given the lack of clear differentiation, use of terms, and reporting of outcomes and impacts in eligible papers. The three manuals were created iteratively. Two researchers (FH, RM or MK) extracted the data independently and, after each review, both researchers discussed the extracted data and resolved disagreements. One these researchers then performed data extraction of the remaining 78 reviews using the established coding manual.

- First analysis round. After data was extracted from 66 included reviews ( $80 \%)$, one researcher (FH) conducted a first analysis, in which codes were removed, refined and/or grouped together. All decisions were reviewed by another researcher (RM, MK or HG), and disagreements were discussed and resolved. We then grouped codes into

(sub)categories. This process resulted in three Excel sheets listing principles, strategies and outcomes/ impacts. Researchers (FH, MK) and research assistants (FR, MK) completed these Excel sheets based on the extracted data of the reviews.

- Second analysis round. After we extracted data from all reviews, one researcher (FH) conducted a second analysis, in which codes were again removed, refined and/or grouped together, and the data was reorganised. All decisions were reviewed by another researcher (RM, MK, HG) and disagreements were discussed and resolved.

- Final analysis round. During the final analysis step, we synthesised the data into workable sets of overarching principles, strategies and outcomes/ impacts. The project leads (FH, HG) synthesised the lists of principles and strategies into two sets of overarching principles and strategies. One project lead (FH) synthesised the list of outcomes/impacts into a set of overarching outcomes/impacts. These overarching findings were then discussed and refined during a meeting with other researchers (MK, KJM, KMS, TN). The overarching principles and strategies were also discussed and refined after a 
meeting with the steering committee (Additional file 1: Appendix 3 and 4). Next, one researcher (IG), who is an IKT and KT expert, reviewed the overarching findings and provided critical feedback on language and clarifications. The project leads ( $\mathrm{FH}, \mathrm{HG}$ ) then refined the overarching findings. Finally, all co-authors and panel members reviewed and approved the final sets of overarching principles, strategies and outcomes/impacts.

\section{Methodological quality appraisal and risk of bias}

The Revised Assessment of Multiple Systematic Reviews (R-AMSTAR) survey [21] was completed independently and in duplicate by two research assistants (CM, KW, PS, $\mathrm{DW}, \mathrm{MB}, \mathrm{FR}, \mathrm{MK}, \mathrm{KL}$ ). If the total scores varied between assessors by more than 5 points (11\%), disagreements were discussed and/or resolved by another researcher (FH, CM). For each review, a total mean score was calculated based on ratings from the two assessors. Following previously described procedures [21], the total mean scores were converted into percentiles and grouped into four grades (A, B, C, D): $\geq 90,80-89,70-79$, and $\leq 69$ percentiles. Grade A includes reviews with the highest rated quality and grade $\mathrm{D}$ includes reviews with the lowest rated quality. Total mean scores were used to identify whether the quality of the review was related to publication year, research area and/or type of review.

Given that the goal of this review was to provide an overview of research partnership literature and its key domains, we did not use the quality assessment scores to synthesise our findings on overarching principles, strategies and outcomes/impacts. Similarly, we did not include a systematic risk of bias assessment. Potential risks of biased results are described in the Discussion section.

\section{Results}

\section{Literature search}

The literature search provided a total of 4677 unique citations (Fig. 1). After screening titles and abstracts, 4188 articles were excluded. The full texts of the remaining 489 papers were retrieved and reviewed. A total of 86 reviews were included in this review of reviews. Agreement between screeners for abstracts was considered as "substantial" for abstract screening (Mean Cohen's Kappa for each of the three screening pairs: 0.71, 0.67, 0.63) and full-text screening (Mean Cohen's Kappa for

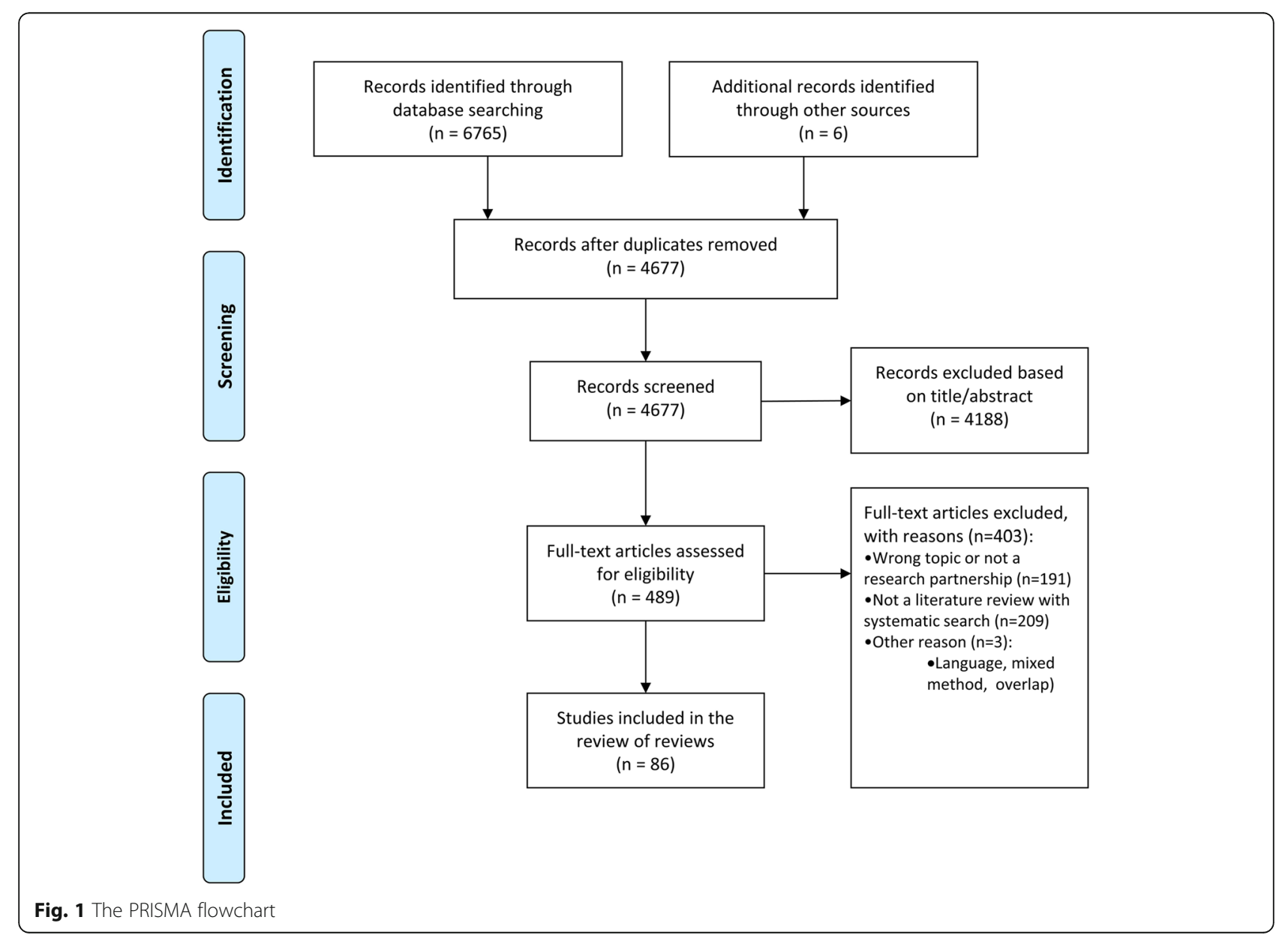


each of the two screening pairs: 0.71, 0.74). References of included reviews are presented in Additional file 1: Appendix 5, and the list of excluded papers is published on OSF [16].

\section{Review characteristics and application areas}

Table 2 provides a summary of the study characteristics of the included reviews. Fourteen (16\%) reviews were published between the years 2004 and 2011, 48 (55\%) reviews were published between the years 2012 and 2016, and the remaining 24 (28\%) reviews were published in 2017 or 2018.

The majority of the reviews were reported as systematic reviews $(n=31)$, literature reviews $(n=27)$ or scoping reviews $(n=14)$. Other review types included narrative reviews $(n=3)$, an integrative review $(n=2)$, rapid reviews $(n=2)$, a critical review $(n=1)$, a framework synthesis review $(n=1)$, a mini-literature review ( $n$ $=1)$, a qualitative review $(n=1)$, a realist review $(n=1)$, a systematic review of reviews $(n=1)$ and a systematic mixed studies review $(n=1)$. Six reviews $[2,35,58,64$, $68,79]$ used a mixed-methods approach, indicating that the literature review was combined with another type of study design (e.g. interview study, case study, Delphi study).

Reviews were published by first authors from the United States $(n=36)$, Canada $(n=17)$, the United Kingdom $(n=14)$, Australia $(n=9)$, New Zealand $(n=$ $2)$, the Netherlands $(n=2)$, Austria $(n=1), \operatorname{Iran}(n=1)$, Germany $(n=1)$, Ghana $(n=1)$, Malaysia $(n=1)$ and Switzerland $(n=1)$. Reviews were conducted in various research areas: population health $(n=34)$, health services $(n=25)$, health and social sciences $(n=16)$, research ethics $(n=7)$ and biomedical research $(n=4)$. Within the population health domain, mental health (n $=5)$, environmental research $(n=3)$ and cancer research $(n=3)$ were the most mentioned subareas. A selection of reviews $(n=25)$ focused on research partnerships with specific groups of stakeholders, such as Indigenous and ethnic minority populations $(n=4)$ [50, 54, 67, 79], children and youth $(n=3)[87,88,104]$, elderly $(n=3)$ $[24,57,85]$, organisations, managers, decision- or policymakers $(n=3)[56,66,76]$, people with intellectual disabilities $(n=3)[65,86,90]$, people with mental illness $(n=3)$, and other vulnerable populations $(n=5)$.

\section{Quality assessment}

The median of the R-AMSTAR total scores was 23.00 (IQR, 20-26) (Table 2). The majority of the reviews were classified in the low or moderate percentile grades - grade D: $n=57$ (66\%), grade C: $n=11(13 \%)$, grade B: $n=8$ (9\%). Ten (12\%) reviews were classified in the highest grade (grade A: $n=10$ ). The R-AMSTAR scores of reviews on research ethics were the lowest compared to reviews in other areas (research ethics, 19.50; biomedical, 20.50; population health, 21.75; health services, 24.00; health and social science, 25.75). The R-AMSTAR scores were highest among systematic reviews compared to the other review types (systematic reviews, 26.00; scoping reviews, 24.00; and literature reviews, 21.50).

\section{Nature of stakeholder engagement}

In 18 of the 86 reviews $(21 \%)$ [1, 34, 47, 49, 53, 54, 59, 61, $62,65,66,73,84,86,88,89,92,100,105]$ detailed information could be extracted on the engagement of stakeholders in different phases of the research process (e.g. planning phase, conducting research, dissemination of findings) (Table 3). Without checking for potential overlap in primary studies included in these reviews, the 18 reviews covered $\sim 870$ primary studies. This set of reviews showed that stakeholders were most frequently reported to be engaged in identifying research questions (423/787, $\sim 54 \%$ ), followed by developing study design and/or methods (393/831, 47\%), data collection (374/824, 45\%), data analysis and/or interpretation (299/709, 42\%), and dissemination of the research findings (214/723, 30\%). In 15 of the $18(83 \%)$ reviews, authors indicated that there was a lack of reporting on how and/or when stakeholders were engaged in different stages of the research process.

\section{Terminology, terms and definitions in research partnership literature}

As expected, different terms and definitions were used to describe different types of research partnership approaches. In $45(52 \%)$ reviews, authors discussed the challenge of conducting a literature review in the area of research partnerships because of the variation in terms and terminology and/or the lack of reporting on details of the research partnerships processes (OSF - Table III). Table 4 provides a list of key terms used for research partnerships by authors of the included reviews. Nineteen reviews $(22 \%)$ used a general overarching term to describe the partnership approach such as 'stakeholder engagement', 'community engagement' or 'service user engagement'. The overarching terms were terms without a specific focus on research and may therefore also be used in other (review) studies to describe other types of partnerships such as stakeholder engagement in healthcare decisions or policy. We included in this review only reviews that focused on or had some focus on stakeholder engagement in the research process. Other terms to describe research partnerships included CBPR $(n=$ $30,35 \%)$, participatory research (PR) $(n=8,9 \%)$, patient and public involvement (PPI) $(n=7,8 \%)$, PAR $(n=5$, $6 \%)$, action research $(n=2,2 \%)$, IKT $(n=1)$ and other terms $(n=12,14 \%)$. While authors tended to use one term throughout their review, we found a large variation in the terms used in the title of the primary studies included in the reviews. 


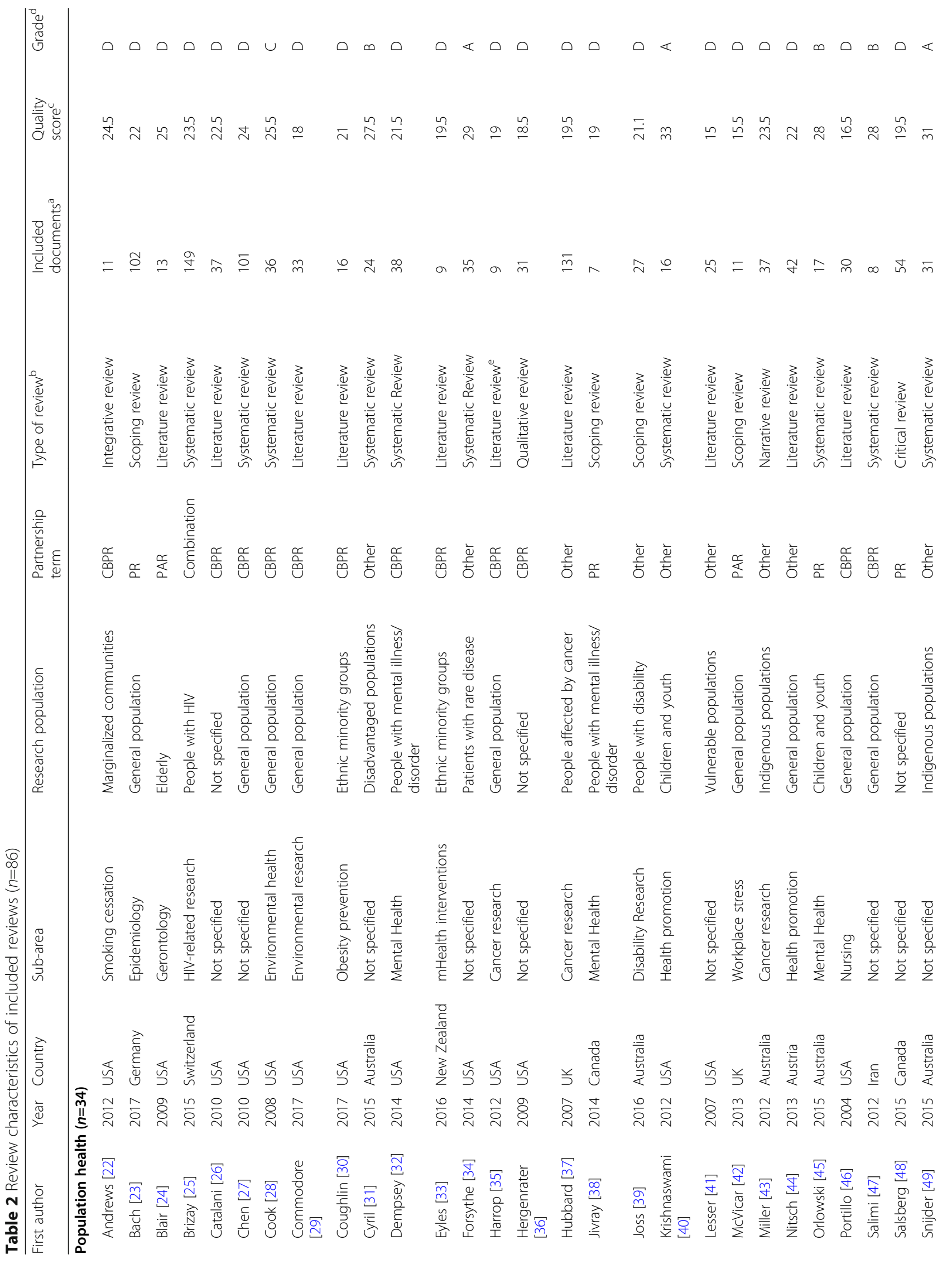




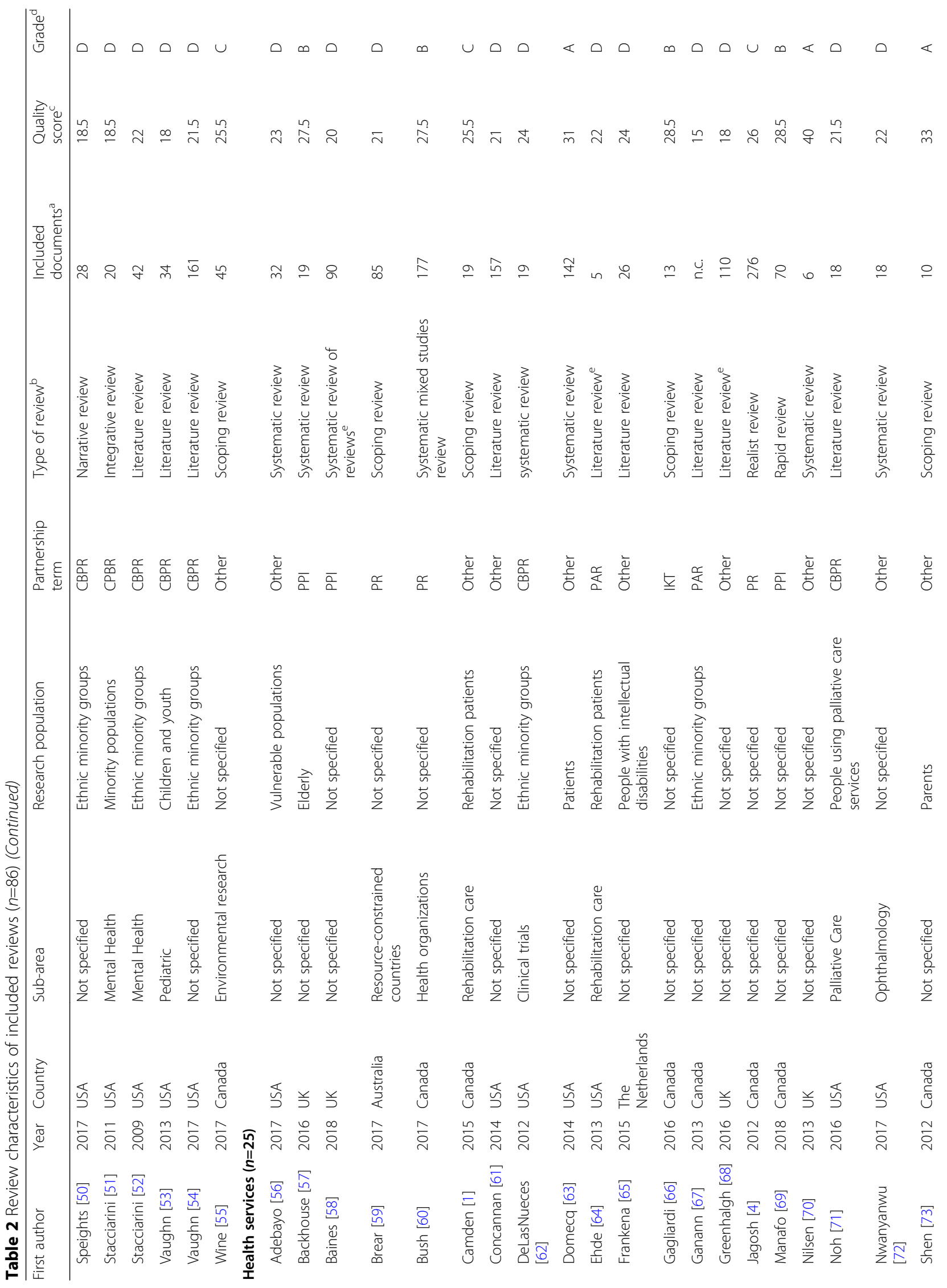




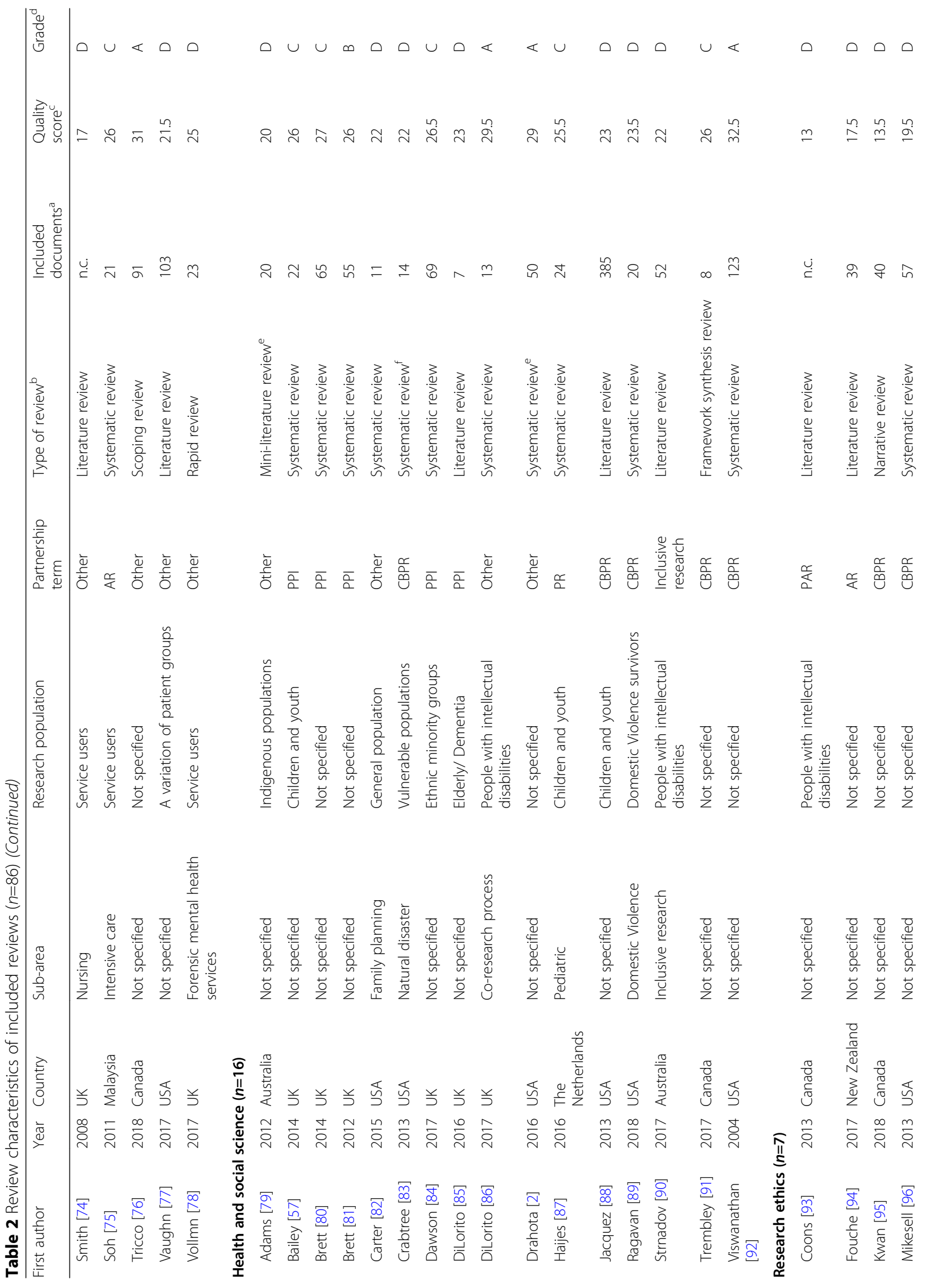




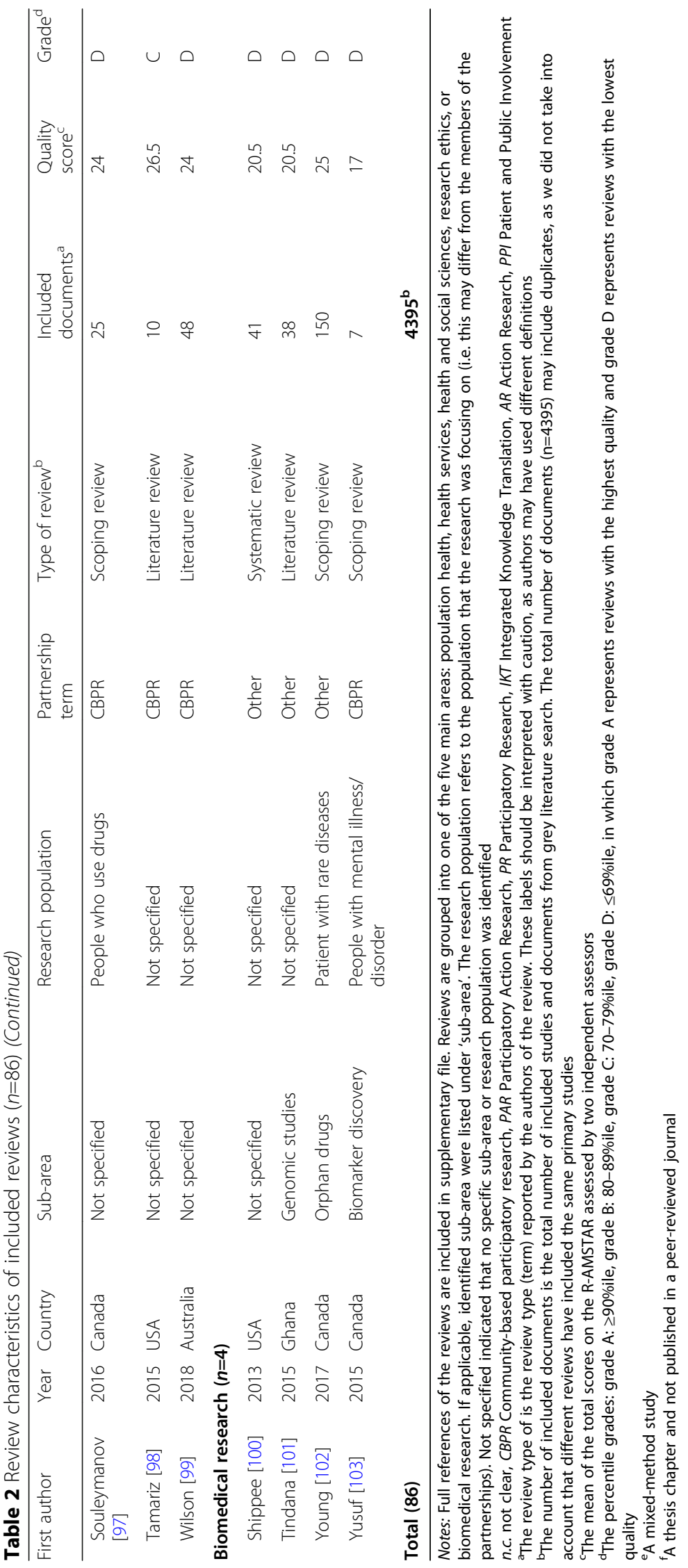


Table 3 Stakeholder engagement in the different phases of the research process based on data from 18 reviews

\begin{tabular}{|c|c|c|c|c|c|c|c|}
\hline \multirow[t]{2}{*}{ First author } & \multicolumn{2}{|l|}{ Planning phase } & \multicolumn{2}{|c|}{ Conducting phase } & \multirow{2}{*}{$\begin{array}{l}\text { Dissemination phase } \\
\text { Dissemination of } \\
\text { research findings }\end{array}$} & \multirow{2}{*}{$\begin{array}{l}\text { Number of } \\
\text { included } \\
\text { studies } \\
\text { (denominator) }\end{array}$} & \multirow{2}{*}{$\begin{array}{l}\text { Lack of } \\
\text { reporting }\end{array}$} \\
\hline & $\begin{array}{l}\text { Identifying research } \\
\text { questions }\end{array}$ & $\begin{array}{l}\text { Developing study } \\
\text { protocol }\end{array}$ & $\begin{array}{l}\text { Data } \\
\text { collection }\end{array}$ & $\begin{array}{l}\text { Data analysis and/or } \\
\text { interpretation }\end{array}$ & & & \\
\hline Brear [59] & $62 \%$ & $45 \%$ & $76 \%$ & $70 \%$ & $32 \%$ & 66 & yes \\
\hline Camden [1] & $53 \%$ & N.R. & $74 \%$ & $58 \%$ & $58 \%$ & 19 & yes \\
\hline $\begin{array}{l}\text { Concannan } \\
\text { [61] }\end{array}$ & $34 \%$ & $44 \%$ & $36 \%$ & N.R. & $9 \%$ & 95 & yes \\
\hline Dawson [84] & $2 \%$ & $71 \%$ & $44 \%$ & $27 \%$ & $24 \%$ & 41 & yes \\
\hline $\begin{array}{l}\text { De Las } \\
\text { Nueces [62] }\end{array}$ & $63 \%$ & $74 \%$ & $63 \%$ & $58 \%$ & $47 \%$ & 19 & yes \\
\hline DiLorito [86] & $15 \%$ & $31 \%$ & $69 \%$ & $54 \%$ & N.R. & 13 & no \\
\hline Forsythe [34] & $54 \%$ & $43 \%$ & $17 \%$ & N.R. & $31 \%$ & 35 & yes \\
\hline Frankena [65] & $42 \%$ & $65 \%$ & N.R. & $38 \%$ & $58 \%$ & 26 & yes \\
\hline Gagliardi [66] & $77 \%$ & $77 \%$ & $15 \%$ & $38 \%$ & $54 \%$ & 13 & yes \\
\hline Jacquez [88] & $77 \%$ & $84 \%$ & $84 \%$ & $54 \%$ & $52 \%$ & 56 & no \\
\hline Ragavan [89] & $60 \%$ & N.R. & N.R. & $50 \%$ & N.R. & 20 & yes \\
\hline Salimi [47] & $38 \%$ & $38 \%$ & $25 \%$ & $25 \%$ & $25 \%$ & 8 & no \\
\hline Shen [73] & $40 \%$ & $90 \%$ & $50 \%$ & $60 \%$ & $50 \%$ & 10 & yes \\
\hline Shippee [100] & $77 \%$ & $14 \%$ & $3 \%$ & $6 \%$ & $6 \%$ & 202 & yes \\
\hline Snijder [49] & $32 \%$ & $42 \%$ & $55 \%$ & N.R. & N.R. & 31 & yes \\
\hline Tricco [76] & $40 \%$ & $49 \%$ & $52 \%$ & $71 \%$ & $44 \%$ & 73 & yes \\
\hline Vaughn [54] & N.R. & $80 \%$ & $76 \%$ & $75 \%$ & N.R. & 83 & yes \\
\hline $\begin{array}{l}\text { Vishwanathan } \\
\text { [92] }\end{array}$ & $47 \%$ & $47 \%$ & $83 \%$ & $65 \%$ & $68 \%$ & 60 & yes \\
\hline Total & $423 / 787, \sim 54 \%$ & $393 / 831, \sim 47 \%$ & $\begin{array}{l}374 / 824, \\
\sim 45 \%\end{array}$ & $299 / 709, \sim 42 \%$ & $214 / 723, \sim 30 \%$ & 870 & $\begin{array}{l}15 / 18 \\
83 \% \text { yes }\end{array}$ \\
\hline
\end{tabular}

Notes: The selected reviews (18 out of 86 reviews) were included in this sub-analyses if the review included information on the engagement of stakeholders in at least two different research phases. Full references of the reviews are included in the supplementary file. The percentages in the table indicate the percentage of included studies that reported on the engagement of stakeholders in that specific phase of the research project. The denominator is different for each review as they represent the number of included studies in the concerning review. As we did not check for overlap in the primary studies included in this sub-set of reviews, the total percentages should be interpreted with caution. The total percentages are, therefore, shown as approximates ( ). The table on OSF includes details on the analysis

N.R. Not reported

${ }^{a}$ Yes indicates that the authors of the review mentioned that there was lack of reporting on how and/or when stakeholders were engaged in the different phases of the research process. No indicates that the authors did not include a statement related to reporting on how and/or when stakeholders are engaged in the different phases of the research process

In 25 of the 86 reviews (29\%) authors described the research partnership approach without providing a clear definition (OSF - Table III). Of this selection, 13 (52\%) reviews focused on CBPR studies. Comparing the definitions between the 4 most frequently used research partnership terms (CBPR, PAR, PR, PPI) showed that definitions of CBPR, PR and PAR varied largely among reviews, while the definitions of PPI were more consistent among the PPI reviews. The majority (71\%) of the reviews describing PPI or a related term (peer research), referred to the INVOLVE definition, which is: "public involvement in research as research being carried out 'with' or 'by' members of the public rather than 'to', 'about' or 'for' them" [106]. While CBPR, PAR, PR and PPI were used by review authors in different areas and in different population groups (e.g. children/youth, ethnic minority groups), the use of a certain key term seemed to be related to a specific research area. To illustrate, CBPR was the most frequently used term within the population health area, while terms PAR and PPI were most frequently used in the health services and health and social science areas (Table 2).

In contrast to PPI reviews, we found that the definitions using the terms CBPR and PAR tended to highlight the engagement of stakeholders in all phases of the research process. We also found that the choice of a term seemed to be related to the country of the first author of the review. Whereas CBPR was most frequently used by North American researchers, PPI was mainly used by researchers in the United Kingdom. Similarly, PR was most frequently used by researchers from Canada and Australia (Fig. 2). Eight reviews [25, 45, 54, 55, 64, 68, 84, 85] provided an overview of differences and/or similarities of the use of 
Table 4 Key terms reported in the included reviews $(n=86)$

\begin{tabular}{|c|c|c|}
\hline Identified key terms & Number of reviews & $\begin{array}{l}\text { Percentage }(\%) \text { of included } \\
\text { reviews }(n=86)\end{array}$ \\
\hline Community-based participatory research (CBPR) & 30 & $35 \%$ \\
\hline \multicolumn{3}{|l|}{ Community-based research $(n=1)$, Photovoice [as CBPR method] $(n=3)$} \\
\hline Overarching terms & 19 & $22 \%$ \\
\hline \multicolumn{3}{|l|}{$\begin{array}{l}\text { Community engagement }(n=5) \text {, community-based organisation engagement }(n=1) \text {, } \\
\text { consumer engagement }(n=1) \text {, community participation }(n=1) \text {, patient and public } \\
\text { engagement }(n=1) \text {, patient involvement }(n=1) \text {, patient engagement }(n=2) \text {, patient } \\
\text { and service user engagement }(n=1) \text {, service user engagement }(n=2) \text {, stakeholder } \\
\text { engagement }(n=3) \text {, user engagement }(n=1)\end{array}$} \\
\hline Participatory research (PR) & 8 & $9 \%$ \\
\hline \multicolumn{3}{|l|}{$\begin{array}{l}\text { Participatory health research }(n=1) \text {, organisational participatory research }(n=1) \text {, } \\
\text { participatory epidemiology }(n=1) \text {, participatory paediatric research }(n=1)\end{array}$} \\
\hline Patient and public involvement (PPI) & 7 & $8 \%$ \\
\hline \multicolumn{3}{|l|}{ Peer research $(n=1)$} \\
\hline Participatory action research (PAR) & 5 & $6 \%$ \\
\hline Action research (AR) & 2 & $2 \%$ \\
\hline Integrated knowledge translation (IKT) & 1 & $1 \%$ \\
\hline Other terms & 13 & $14 \%$ \\
\hline \multicolumn{3}{|l|}{$\begin{array}{l}\text { Inclusive research }(n=2) \text {, co-research }(n=2) \text {, community-engaged research }(n=2) \text {, } \\
\text { co-creation }(n=1) \text {, community-academic partnerships }(n=1) \text {, community-academic } \\
\text { research partnerships }(n=1) \text {, participatory evaluation }(n=1) \text {, research partnerships }(n=1) \text {, } \\
\text { collaborative research }(n=1) \text {, involvement in research }(n=1)\end{array}$} \\
\hline Combination of terms ${ }^{a}$ & 1 & $1 \%$ \\
\hline
\end{tabular}

Notes: The key term is the term used to describe the study aims, Methods and Results sections. This term may differ from the term used in the primary studies included in the review. Additional information: Viswanathan et al. [92] published a CBPR definition based on 55 articles. Drahota et al. [2] presented a consensusbased term and definition of community-academic partnership

a This review [25] focused specifically on a combination of terms for research partnerships

different research partnership terms and/or definitions (Additional file 1: Appendix 6).

\section{Terms and terminology key domains}

We identified a variety of terms related to principles, strategies, outcomes and impacts of research partnerships (Additional file 1: Appendix 7), indicating that authors used different terms to describe the same concept. To illustrate, 50 out of 80 identified outcome/impact codes (63\%) were mentioned by authors of the included reviews using at least two different terms (outcomes, impacts, benefits).

\section{Principles}

After the first analysis round, we extracted 166 principles from the included reviews (OSF - Table IV). The second analysis round resulted in a list of 98 principles and 45 linking values (e.g. trust, respect, credibility, empowerment). We synthesised the 98 principles into 17 overarching principles, and then grouped them into one of the following subcategories (1) relationship between researchers and stakeholders; (2) co-production of knowledge; (3) meaningful stakeholder engagement; (4) capacity-building, support and resources; (5) communication between researchers and stakeholders; and (6) ethical issues of collaborative research activities.
Table 5 describes the final overarching principles. In 7 reviews, no principles were identified (OSF - Table V). The top 3 most frequently identified principles from the included reviews related to the following overarching principles: (1) partners build and maintain relationships based on trust, credibility, respect, dignity and transparency ( $n=180$ of 935 identified principles, 19\%); (2) partners co-produce knowledge and meaningfully engage stakeholders at each phase of the research process $(n=$ 103, 11\%); and (3) partners are flexible and creative in collaborative research activities and tailor the approach $(n=72,8 \%)$.

Additional file 1: Appendix 8 describes 13 reviews (13/86; $15 \%)$ that explicitly focused on principles of research partnerships [24, 50-52, 55, 58, 68, 72, 83, 89, 96, 101, 103].

\section{Strategies}

After the first analysis round, we extracted 115 strategies from the included reviews (OSF - Table VI). The next round resulted in a list of 111 strategies, which we then synthesised into 11 overarching strategies. To help organise these strategies, we grouped them into one of the following subcategories: (1) relationship between researchers and stakeholders; (2) capacity-building, support and resources; (3) communication between 


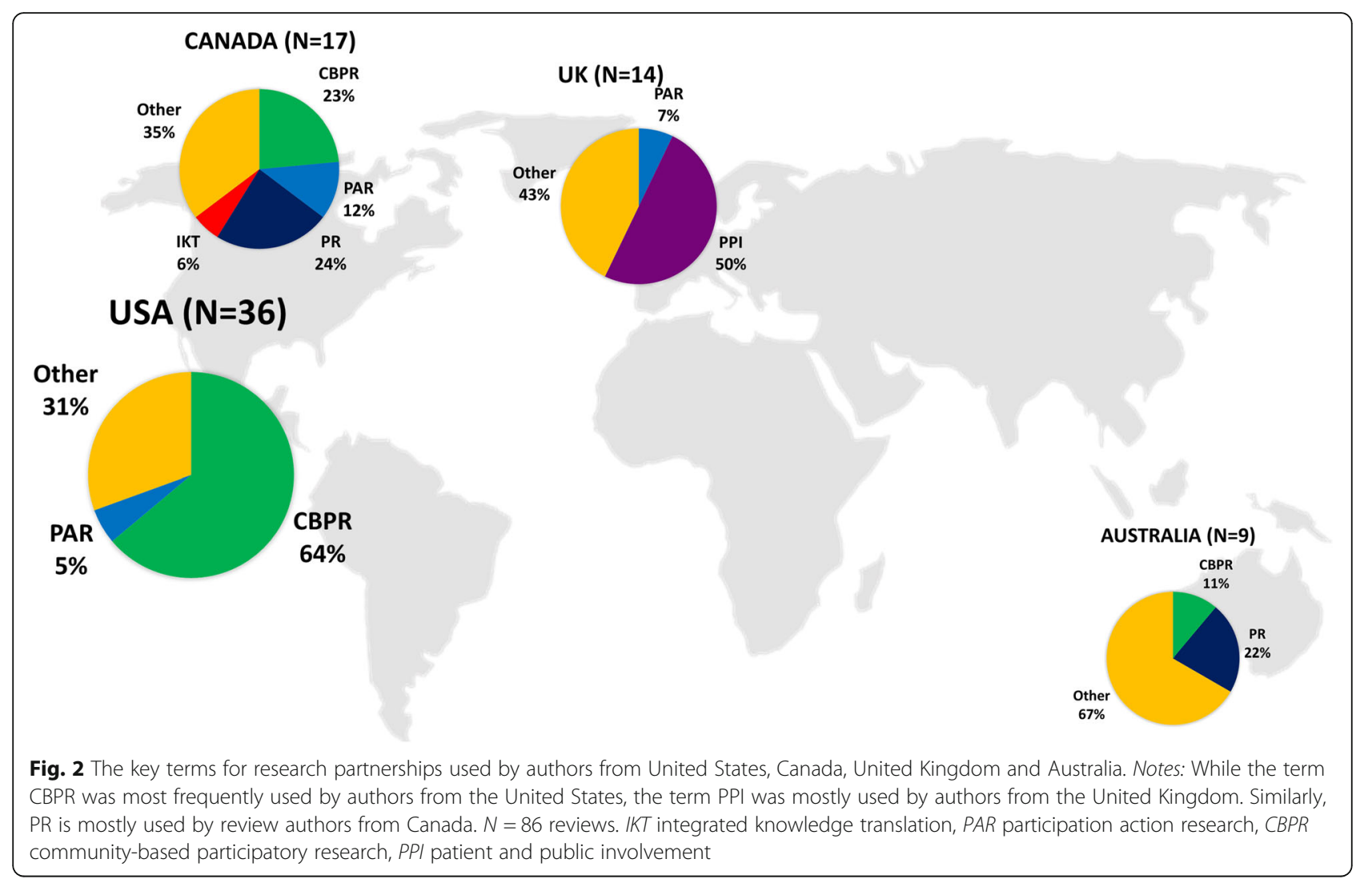

researchers and stakeholders; (4) stakeholder engagement in the planning of the research; (5) stakeholder engagement in conducting the research; and (6) stakeholder engagement in dissemination and application of the research.

While the first three subcategories include strategies that can be used throughout the research process (e.g. relationship, capacity-building, communication), the latter three subcategories include strategies for specific phases of the research project (planning, conducting, dissemination or application). Table 6 describes the final overarching strategies and related subcategories. From almost all of the reviews ( $n=85,99 \%)$, we extracted at least one strategy (OSF-Table V). The five most frequently identified strategies from the included reviews related to the following overarching strategies: (1) use of a variety of communication strategies $(n=183$ of 995 identified strategies, $18 \%$ ); (2) stakeholder engagement in the planning of the research $(n=178,18 \%)$; (3) stakeholder engagement in conducting the research $(n=159$, $16 \%)$; (4) stakeholder engagement in dissemination and application of the research $(n=155,16 \%)$; and (5) provide opportunities to educate and train all team members $(n=87$; 9\%).

Three Canadian reviews $[1,48,76]$ reported the highest number of different strategies (Additional file 1: Appendix 9).

\section{Outcomes and impacts}

One or more outcomes/impacts were extracted from the majority of the reviews ( $n=74,86 \%$ ) (OSF-Table VII). After the analyses, we identified 82 outcomes/impacts from the included reviews. Of these, we classified 56 as beneficial outcomes/impacts (68\%) and 26 as challenging or negative outcomes/impacts (32\%). We synthesised these outcomes/impacts into 20 overarching outcomes/ impacts and clustered them into the following five subcategories: (1) outcomes and impacts on researchers conducting the partnership research (individual-level); (2) outcomes and impacts on the stakeholder(s) (individuallevel); (3) outcomes and impacts on the relationship between researchers and stakeholders (partnership-level); (4) outcomes and impacts on the broader community or society; (5) outcomes and impacts on the research process.

Table 7 outlines the overarching outcomes/impacts including the related subcategories. The top 5 most frequently identified outcomes/impacts from the included reviews were related to the following overarching outcomes/impacts: (1) stakeholders experienced personal benefits from working in a research partnership ( $n=104$ of $675 ; 15 \%)$; (2) partners reported that the research partnership can create high quality research $(n=80,12 \%)$; (3) stakeholders experienced increased capacity, knowledge and skills related to research processes $(n=74,11 \%)$; (4) partners reported that the research partnership can create increased capacity to conduct 
Table 5 Overarching principles of research partnerships

\begin{tabular}{|c|c|c|}
\hline No & Principles & Subcategory \\
\hline $1 \mathrm{a}$ & $\begin{array}{l}\text { Partners build and maintain relationships based on trust, credibility, } \\
\text { respect, dignity, and transparency }\end{array}$ & Relationship between researchers and stakeholders \\
\hline $1 \mathrm{~b}$ & $\begin{array}{l}\text { Partners acknowledge, reward and value the diverse expertise of the } \\
\text { partnership and its members }\end{array}$ & \\
\hline $1 c$ & $\begin{array}{l}\text { Partners share in decision-making and leadership of different research } \\
\text { activities }\end{array}$ & \\
\hline $1 d$ & $\begin{array}{l}\text { The partnership addresses power dynamics within the team and aim } \\
\text { to promote equity, self-determination and/or social justice }\end{array}$ & \\
\hline 1e & $\begin{array}{l}\text { The partnership ensures representation and/or inclusivity and addresses } \\
\text { disciplinary and sectoral issues }\end{array}$ & \\
\hline $2 a$ & $\begin{array}{l}\text { Partners co-produce knowledge and meaningfully engage stakeholders } \\
\text { at different phases of the research process }\end{array}$ & Co-production of knowledge \\
\hline $2 b$ & $\begin{array}{l}\text { Partners ensure that all members of the partnership have ownership } \\
\text { over the data and resulting knowledge products }\end{array}$ & \\
\hline $2 c$ & $\begin{array}{l}\text { Partners strive to balance the need for scientific rigour alongside the } \\
\text { practical need for actionable knowledge }\end{array}$ & \\
\hline $2 d$ & $\begin{array}{l}\text { Partners ensure the long-term implementation of the findings in real } \\
\text { world settings and systems }\end{array}$ & \\
\hline 3a & $\begin{array}{l}\text { Partners carefully plan and regularly reflect on their strategic approach } \\
\text { to collaboration }\end{array}$ & Meaningful stakeholder engagement \\
\hline $3 b$ & $\begin{array}{l}\text { Partners are flexible and creative in the collaborative research activities } \\
\text { and tailor the approach }\end{array}$ & \\
\hline $3 c$ & Researchers and stakeholders benefit from the partnership & \\
\hline $3 d$ & $\begin{array}{l}\text { The partnership identifies the stakeholder's needs and makes sure that } \\
\text { the research is relevant for the stakeholders }\end{array}$ & \\
\hline $4 a$ & Partners build capacity among all members of the partnership & Capacity-building, support and resources \\
\hline $4 b$ & $\begin{array}{l}\text { Partners ensure bidirectional exchange of skills, knowledge and } \\
\text { capacity between members of the partnership }\end{array}$ & \\
\hline $5 a$ & $\begin{array}{l}\text { The partnership fosters regular, open, clear and honest communication } \\
\text { between its members }\end{array}$ & Communication between researchers and stakeholders \\
\hline 6 & Partners address ethical issues related to the collaborative research activities & Ethical issues of collaborative research activities \\
\hline
\end{tabular}
Note: Partners include both researchers and stakeholders. We synthesised the overarching principles from 98 principles. The steps taken to synthesise these overarching principles are described in OSF-Table IV. To help organise these principles, we grouped them into six subcategories. The principles are numbered for feasibility reasons. The order of the principles does not relate to the frequencies

and disseminate the research $(n=69,10 \%)$; and (5) partners reported that the research partnership can create system changes or action $(n=65,10 \%)$.

Appendix 10 outlines a description of highlighted reviews specifically focusing on outcomes and/or impacts of research partnerships $[4,28,60,66,80,81]$.

\section{Potential challenging or negative outcomes/impacts}

Although the reviews predominantly reported on the beneficial outcomes/impacts of research partnerships, we also identified potential challenging or negative outcomes/impacts (Table 7). We extracted potential challenging outcomes/impacts at an individual researcher level (e.g. additional time and financial burden, uncomfortable feelings associated with power-sharing), at a partnership level (e.g. conflict between researchers and stakeholders) as well as at the research project level (e.g. biased data). We extracted potential challenging or negative outcomes/impacts at the individual stakeholder level (e.g. feelings of tokenism, disempowerment, overburdened) in reviews related to special populations such as children and youth [87, 104], parents [73], people with intellectual disabilities $[65,86,90]$, ethnic minority groups and patient groups $[1,80]$. We did not identify potential negative outcomes/impacts at the individual stakeholder level in reviews $(n=3)$ on partnerships with organisations or policy-makers, decision-makers or managers $[60,66,105]$.

\section{Discussion}

This review of reviews provides a guide through the diverse literature on research partnerships in different research areas and with different stakeholder groups. We identified an extensive set of research partnership principles, strategies, outcomes and impacts from the included reviews. 
Table 6 Overarching strategies of research partnerships

\begin{tabular}{|c|c|c|c|}
\hline No. & Strategies & Subcategory & \\
\hline $1 a$ & $\begin{array}{l}\text { Initiate partnership and identify the team members; the partnership can } \\
\text { be initiated by researchers or stakeholders; researchers can use targeted } \\
\text { or open strategies to identify the stakeholders }\end{array}$ & $\begin{array}{l}\text { Relationship between } \\
\text { researchers and stakeholders }\end{array}$ & $\begin{array}{l}\text { Strategies throughout } \\
\text { the research process }\end{array}$ \\
\hline $1 b$ & $\begin{array}{l}\text { Monitor, experiment with and evaluate the collaborative research activities } \\
\text { on an ongoing basis }\end{array}$ & & \\
\hline $1 c$ & $\begin{array}{l}\text { Work together to develop and define norms, rules and expectations in } \\
\text { terms of timelines and tasks; this includes defining the level of stakeholders' } \\
\text { engagement, roles and commitment }\end{array}$ & & \\
\hline $1 d$ & $\begin{array}{l}\text { Use a variety of activities to foster collaboration, communication and respect } \\
\text { amongst the team members; strategies can include, but are not limited to, } \\
\text { creating a common language, negotiating and addressing conflict, tailoring } \\
\text { meets to the needs of the team, and providing opportunities to socialise }\end{array}$ & & \\
\hline $2 a$ & $\begin{array}{l}\text { Provide opportunities to educate and train all team members; this strategy } \\
\text { may include training that supports capacity for collaboration or research } \\
\text { methods }\end{array}$ & $\begin{array}{l}\text { Capacity-building, support } \\
\text { and resources }\end{array}$ & \\
\hline $2 b$ & $\begin{array}{l}\text { Provide time, resources and funding to support the collaborative research } \\
\text { activities; stakeholders may be paid for engagement in the research process }\end{array}$ & & \\
\hline $2 c$ & $\begin{array}{l}\text { Provide practical and emotional support to stakeholders to help overcome } \\
\text { barriers to engagement }\end{array}$ & & \\
\hline $3 a$ & $\begin{array}{l}\text { Use a variety of methods to facilitate communication amongst team members; } \\
\text { strategies include, but are not limited to, verbal methods (e.g. structured } \\
\text { meetings, brainstorm sessions), written methods (e.g. email discussions, } \\
\text { surveys) and visual methods (e.g. photovoice); this communication can be } \\
\text { done in-person or via mediated methods (e.g. teleconference, online) }\end{array}$ & $\begin{array}{l}\text { Communication between } \\
\text { researchers and stakeholders }\end{array}$ & \\
\hline $4 a$ & $\begin{array}{l}\text { Strategies include, but are not limited to, stakeholder engagement in identifying } \\
\text { or refining the 'research questions', stakeholder engagement in development } \\
\text { the 'research protocol', stakeholder engagement developing or refining } \\
\text { 'research instruments' (e.g. questionnaires, interview guides) and stakeholder } \\
\text { engagement in development of participant 'information material' (e.g. informed } \\
\text { consent) }\end{array}$ & $\begin{array}{l}\text { Stakeholder engagement in } \\
\text { the planning of the research }\end{array}$ & $\begin{array}{l}\text { Strategies at specific phases } \\
\text { in the research process }\end{array}$ \\
\hline $5 a$ & $\begin{array}{l}\text { Strategies include, but are not limited to, stakeholder engagement in 'data } \\
\text { collection' (e.g. recruitment of participants, study outcomes, conducting } \\
\text { interviews, conducting literature review), stakeholder engagement in data } \\
\text { analysis, and interpretation of findings }\end{array}$ & $\begin{array}{l}\text { Stakeholder engagement in } \\
\text { conducting the research }\end{array}$ & \\
\hline $6 a$ & $\begin{array}{l}\text { Strategies include, but are not limited to, stakeholder engagement in 'writing } \\
\text { reports or scientific papers' (e.g. stakeholder is co-author on a scientific paper), } \\
\text { stakeholder engagement in 'presenting findings' to academic and community } \\
\text { audiences, stakeholder engagement in a 'developing and implementation } \\
\text { action plan' to ensure findings are used, and stakeholders use the findings } \\
\text { to create change }\end{array}$ & $\begin{array}{l}\text { Stakeholder engagement in } \\
\text { dissemination and application } \\
\text { of the research }\end{array}$ & \\
\hline
\end{tabular}

Note: Partners include both researchers and stakeholders. We synthesised the overarching strategies from 111 strategies extracted from the included reviews. The steps taken to synthesise these overarching strategies are described in OSF-Table V. To help organise these strategies, we grouped them into six subcategories.

The strategies are numbered for feasibility reasons. The order of the strategies does not relate to the frequencies

\section{Principles and strategies}

We synthesised information on principles and strategies from a variety of research partnership approaches into 17 overarching principles and 11 overarching strategies. As these overarching principles and strategies are based on reviews (instead of primary studies), we synthesised them in a broad and general way. As such, the overarching principles and strategies may not directly apply to all research partnerships as these are context dependent. Three key research partnership characteristics may guide the contextualisation of these principles and strategies. The first characteristic is 'the stakeholder group'. To illustrate, we saw that different principles and strategies are used when working with different groups of stakeholders (e.g. people with lived experience with a health condition versus policy-makers versus community organisations). The second characteristic is 'the level of engagement'. Principles and strategies should align with the level of stakeholder engagement, which may be determined by using the five engagement categories of the widely used IAP2 Spectrum of Public Participation (e.g. inform, consult, involve, collaborate, empower) [107] or using other engagement frameworks (e.g. [3, 108, 109]). The third characteristic is 'the research phase'. While some principles and strategies may be applicable throughout the research phase, others may be more important or applicable for specific phases of the research project [76]. 
Table 7 Overarching outcomes and impacts

\begin{tabular}{|c|c|}
\hline Beneficial outcomes/impacts & Challenging outcomes/impacts \\
\hline $\begin{array}{l}\text { Researchers have experienced increased 'capacity, } \\
\text { knowledge and skills' related to planning, conducting } \\
\text { and disseminating research in partnership with } \\
\text { stakeholders; this may include a better understanding } \\
\text { of the area under study and/or an increased awareness } \\
\text { of community issues }\end{array}$ & \\
\hline $\begin{array}{l}\text { Researchers have experienced 'personal benefits' from } \\
\text { working in a research partnership such as enhanced } \\
\text { motivation for the research project and/or lightening } \\
\text { of the workload }\end{array}$ & $\begin{array}{l}\text { Researchers have experienced 'personal challenges' } \\
\text { when working in a research partnership such as } \\
\text { uncomfortable feelings when sharing power over } \\
\text { the research and/or the additional time and financial } \\
\text { burden associated with the research partnership }\end{array}$ \\
\hline
\end{tabular}

Stakeholders have experienced increased 'capacity, knowledge and skills' related to research processes; this may include a better understanding of the area under study and/or an increased awareness to the application of the research

Stakeholders have experienced a more 'positive attitude' towards research and researchers

Stakeholders have reported better access to information relevant for them such as information on treatments or management of specific diseases or illnesses

Stakeholders have experienced 'personal benefits' from working in a research partnership; examples include, but are not limited to, feeling empowered, feeling valued, increased confidence, increased sense of accomplishment, extended social and support network, and/or increased chances on future employment

Partners have reported that the research partnership can 'have positive outcomes/impacts on the relationship' between researchers and stakeholders; examples include, but are not limited to, greater partnership synergy, mutual respect, mutual understanding of work style, language, needs and constraints, and/or can create sustainable collaborations

Partners have reported that the research partnership can 'create system changes or action' by influencing policy-making, improving community services, improving health-related outcomes for community, and/or creating capacity to sustain the projects

Partners have reported that the research partnership can 'increase capacity' in the community by creating better understanding of research in the community and/or increased awareness and knowledge of the study topic

Partners have reported that the research partnership can increase 'community empowerment'

Partners have reported that the research partnership can 'create community ownership' of the research

Partners have reported that the research partnership can increase the 'acceptability and trust of the research' in the community

Stakeholders have experienced 'personal challenges' when working in a research partnership, such as feelings of not being listened to, not being empowered, not being taken seriously, frustrated and/or dissatisfied about the research processes

Stakeholders have experienced 'feeling overburdened' by tasks and responsibilities

Partners have reported that the research partnership may result in 'conflicts' between researchers and stakeholders

\section{Subcategory}

Outcomes and impacts on

researchers conducting partnership research (individual level)

Outcomes and impacts on stakeholders involved in research partnerships (individual level)
Outcomes and impacts on the relationship between researchers and stakeholders (partnership level)
Outcomes and impacts on the community or society
Partners have reported that research partnership may create 'challenging outcomes or impacts on the community' such as increased time and financial burden on the community organisations, further stigmatisation of the group and/or negative research findings 
Table 7 Overarching outcomes and impacts (Continued)

\begin{tabular}{|c|c|c|}
\hline Beneficial outcomes/impacts & Challenging outcomes/impacts & Subcategory \\
\hline $\begin{array}{l}\text { Partners have reported that the research partnership } \\
\text { can create 'relevant and useful research findings' }\end{array}$ & & $\begin{array}{l}\text { Outcomes and impacts } \\
\text { on the research process }\end{array}$ \\
\hline \multicolumn{3}{|l|}{$\begin{array}{l}\text { Partners have reported that the research partnership } \\
\text { can create 'high quality research' by generating credible } \\
\text { and valid data, developing effective interventions, and/or } \\
\text { unearthing new information; the partnership can also } \\
\text { general new and other projects }\end{array}$} \\
\hline \multicolumn{3}{|l|}{$\begin{array}{l}\text { Partners have reported that the research partnership can } \\
\text { create 'increased capacity' to conduct and disseminate } \\
\text { the research }\end{array}$} \\
\hline & $\begin{array}{l}\text { Partners have reported that the research } \\
\text { partnership may lead to negative outcomes } \\
\text { or impacts, including biased data or tokenism }\end{array}$ & \\
\hline
\end{tabular}

Notes: Partners include both researchers and stakeholders. As the literature did not differentiate between outcomes and impacts and these terms were used interchangeably throughout the literature, we did not distinguish our results between outcomes and impacts. Challenging outcomes/impacts were also reported in the literature as (potential) negative outcomes/impacts. The order of the outcomes/impacts does not relate to the frequencies

To gain a better understanding of which principles and strategies are successful in which contexts and under which circumstances, more detailed reporting and consistent use of related terms across the research partnership literature at both the individual study- and review-level is required. Our review might be used as a first step in developing a classification system of principles and strategies for research partnership approaches to improve the consistency of reporting (e.g. similar to Michie's behaviour change technique taxonomy [110] and Hoffman et al. [111] reporting for interventions). However, it is likely that further examination of primary research studies are needed before such classification systems can be established.

\section{Outcomes and impacts}

Our results show that outcomes and impacts are not well-differentiated and that these terms are used interchangeably throughout the reviews examined. This finding may suggest that authors are not aware of potential conceptual differences between outcomes and impacts. To gain a better understanding about specific outcomes and specific impacts of research partnerships, further research is needed in which data related to these key domains are extracted from primary studies (as opposed to reviews) using specific definitions [11].

While the literature predominantly highlighted the positive outcomes and impacts of research partnership approaches, we found that reviews also reported on potential challenging or negative outcomes/impacts (Table 7). The question then arises of whether such potential negative outcomes/impacts may be a result of poor relationships between researchers and stakeholders (i.e. failed partnerships), poor co-production processes, a combination of both and/or other partnership influences. In our review of reviews, we were unable to answer this question, because of the high-level focus of this review. A different research design, such as a realist review [112, 113] or interviews, would be more appropriate to answer these type of research questions. While more in-depth studies are needed to explore how, when and why research partnership approaches are perceived to be beneficial or not, a recent commentary paper by Oliver et al. [114] provides initial guidance.

Studies evaluating research partnership approaches are scarce and mainly focus on perceived and self-reported outcomes/impacts. More in-depth, prospective multicase studies are needed to advance the science of research partnerships (e.g. [7, 15]). To provide further guidance on 'how to study a research partnership', our subsequent scoping reviews will identify tools, methods and methodologies to evaluate research partnership approaches [11]. These insights should help researchers to better monitor, evaluate and report their partnership approaches as well as contribute to more high-quality data on outcomes and impacts of research partnership approaches at both study and review level.

\section{Limitations and strengths}

The first limitation relates to the qualitative nature of our data. We extracted qualitative data from the included reviews without verifying the data with the primary studies. This may have resulted in inaccurate and/ or biased findings. Moreover, the interpretations of the reviews may be flawed due to a lack of details and/or differences in research partnership (domain) terms, terminology and definitions used in the primary studies and/or reviews. For this reason, we were reluctant to report on the number of times (frequencies) that a specific finding (principles, strategies, outcome, impact) had been reported in the reviews. We aimed to address this limitation by focusing this review on high-level findings on research partnerships domains without providing details on what worked best under which circumstances. 
The second limitation relates to our eligibility criteria. We excluded articles that did not use a systematic search (e.g. $[115,116])$ and/or used other types of partnerships (e.g. public-private partnerships, partnership in healthcare, partnership in education). We also excluded reviews that did not include a specific aim or sub-aim related to research partnerships. By excluding these and other reviews, we may have missed relevant information related to key domains of research partnerships.

The third limitation relates to our search strategy. In line with the focus on our review, we used a very highlevel search strategy to capture relevant reviews. We omitted some relevant concepts in our search strategy, including terms related to 'stakeholder engagement', 'patient and public involvement', and 'implementation'. By doing so, we realised and accepted that we might have missed potentially relevant reviews in our first step of synthesising the research partnership literature, in particular those that were reviewing particular partnership methodologies in the research process. For our next steps, which includes conducting three scoping reviews, we have developed a series of more comprehensive search strategies informed by our findings from this review of reviews. The steps taken to develop the search strategy capturing the concept of 'research partnership' are described elsewhere [117]. We would encourage individuals interested in doing a review related to research partnership to use and build upon our comprehensive search strategy.

The fourth limitation relates to our extraction process. As the extraction process was time consuming because of the qualitative nature of the data, we did not extract the data in duplicate. However, the data extraction process began only after consensus-driven and reliable coding methods were established. The synthesised processes of our overarching principles, strategies and outcomes/impacts were conducted by project leads (FH, HG) and critically reviewed by other members of the research team. To improve transparency, the steps taken to synthesise our overarching findings are available on OSF.

The final limitation relates to our quality assessment process. We used a quality assessment tool (RAMSTAR) that was primarily developed to assess the quality of systematic reviews in clinical settings. As different review types have different goals (e.g. summarising existing knowledge versus data aggregation) with different corresponding methods, our quality assessment tool may not be preferred to assess the quality of other types of reviews (e.g. scoping reviews, narrative reviews, realist reviews) [118]. Because of the limitations of our quality assessment approach, we did not use these results to synthesise our overarching findings. Alternatively, we included quality assessment scores and corresponding percentile grades to orient the reader.
This review has several strengths. First, this is the first review of reviews focusing on different types of research partnerships in a variety of research areas and thus may serve as a guide through the research partnership literature.

Second, we used a collaborative research approach (Coordinated Multicenter Team) [11] and we engaged stakeholders (steering committee) (Additional file 1: Appendix 3) in different phases of the project (Additional file 1: Appendix 4), strengthening our procedures and findings.

Third, our processes are clearly documented and presented transparently. Details related to our search strategy as well as different steps in the analysis process are available on OSF. By doing so, other researchers who are planning to synthesise the literature on research partnerships can build upon our methods and findings.

Finally, this review is part of a collaborative review approach and has both theoretical and practical contributions. To the research partnership literature, our findings provide new insights on key domains (principles, strategies, outcomes, impacts) of research partnership approaches across a variety of research areas. We hope that our collaborative review efforts will contribute to better and more consistent reporting of the research partnership literature and ultimately advance the science of research partnerships. Moreover, the findings from this review may help researchers and stakeholders from different research areas to plan, conduct and/or disseminate research in partnership (Table 8). Ultimately, we hope that our collaborative review efforts will contribute to improving the quality and conduct of research partnerships in many different areas across the world.

\section{Future directions}

Due to the variation in terms, terminology and definitions in combination with the lack of reporting on details related to the research partnership approaches, we were unable to create a systematic overview of the differences and similarities of the different research approaches. Further research using different research designs is needed to identify and understand the similarities and differences between different partnership approaches (e.g. [119]). We found that the use of partnership terms seemed to be associated with the research area (Table 2) and country of the first author (Fig. 2). To ensure the consistency of terms and definitions, researchers from different areas and from different countries should work together to build consensus on common research partnership terms, terminology and definitions.

As funding agencies are increasingly promoting the use of research partnership approaches, additional guidance may be needed to support researchers and stakeholders in establishing and conducting partnered 
Table 8 Initial guidance for the use of our findings by research partnerships

\begin{tabular}{|c|c|}
\hline \multicolumn{2}{|r|}{ Summarising steps of research partnership processes } \\
\hline & $\begin{array}{l}\text { Build and maintain relationships between academic researchers } \\
\text { and stakeholders; the relationship may be built upon values important } \\
\text { for all partnership members such as trust, respect, transparency, } \\
\text { credibility }\end{array}$ \\
\hline & $\begin{array}{l}\text { Determine the level of stakeholder engagement (e.g. inform, } \\
\text { consult, involve, collaborate, empower) for each phase in the research }\end{array}$ \\
\hline
\end{tabular}

Step Contextualisation: Select and/or adapt principles and strategies relevant for your research partnership in your research area: principles and strategies need to align with the desirable level of stakeholder engagement and need to align with the needs and preferences of all members of the partnership; principles and strategies may differ between different phases of the research process

Step Communicate, monitor, and report the principles, strategies,

4 outcomes and impacts of the research partnership; this information will provide the opportunities to learn from your own as well as from others successes and challenges related to collaborative research activities, and may contribute to advancing the science of research partnerships
Additional information

Table 7 provides strategies related to building and maintaining relationships; OSF-Table IV provides a list of identified principles and values

Table 7 provides strategies for different phases in the research process and OSF-Table IV provides a list of related principles; two reviews $[25,76]$ included other examples of detailed frameworks of the use of collaborative research activities in different phases of the research process

Table 2 provides an overview of the research areas and population of the included reviews; in addition to the related reviews, we recommend exploring individual studies that used or evaluated research partnership approaches specifically related to your research area and/or population; an example of the contextualisation for spinal cord injury research partnerships is described elsewhere [OSF]

To support consistent reporting, Additional file 1: Appendix 1 provides our consensus-based guiding framework including definitions of the key domains of research partnerships

Notes: We identified these four steps based on our own experiences from reviewing the research partnership literature as well as our own experiences with conducting and disseminating research in partnerships; these steps may help readers to tailor our overarching findings of research partnerships processes to their local context. Our next umbrella review will include more specific recommendations

research. Therefore, future research should focus on the development of evidence-based support services, including tools and resources for research partnerships related to the key domains (principles, strategies, outcomes, impacts).

Our overarching findings are extracted from the diverse research partnership literature and are not tailored to specific groups of stakeholders or specific research areas. Additional efforts, including the contextualisation of research partnership processes, may be needed. Based on our own experiences, we identified four steps that may be used to tailor our overarching findings of research partnership processes to local settings (Table 8 ).

\section{Conclusions}

This review of reviews is the first to present the overarching principles, strategies, outcomes and impacts of research partnerships. This review is unique in scope as we synthesised the literature in different research areas that included different stakeholder groups. By doing so, this review begins to map the diverse research partnership literature. The overarching principles, strategies and outcomes/impacts can be a first step towards creating a classification system of these domains, which may be used to guide researchers and partnerships, improve the consistent reporting of these domains in the literature, and will ultimately help to advance the science and practice of research partnerships.

\section{Supplementary information}

Supplementary information accompanies this paper at https://doi.org/10. 1186/s12961-020-0544-9.

\section{Additional file 1.}

\section{Abbreviations}

IKT: Integrated knowledge translation; PAR: Participatory action research; PR: Participatory research; CBPR: Community-based participatory research; PPI: Patient and public involvement; OSF: Open Science Framework; SCl: Spinal cord injury

\section{Acknowledgements}

$\mathrm{SCl}$ Guiding Principles Consensus Panel includes Kim Anderson (NASCIC), Hugh Anton (ICORD, UBC Medicine), Peter Athanasopoulos (SCI Ontario, SCI Solutions Alliance), John Chernesky (RHI, NASCIC), Susan Forwell (ICORD, UBC Occupational Therapy), Jocelyn Maffin (SCI BC), Kathleen Martin Ginis (UBC, ICORD), Christopher B McBride (SCI Canada, SCI BC), Ben Mortenson (UBC, ICORD) and Rhonda Willms (ICORD, GF Strong, UBC Medicine). The authors would like to thank Christine J. Neilson for her contribution to the conceptual design and conduct of the search strategy, Leah Crocket for her involvement in conceptualisation of the protocol, and Francisca Rodrigues Trigo Pereira, Michael Kennefick, Parneet Sabhi, Dawn Steliga, Kelsey Wuerstl, Molly Beauregard and Clayton March for assisting in data extraction.

\section{Authors' contributions}

Authors' contributions are listed using the CRediT taxonomy criteria (https:// www.casrai.org/credit.html). FH participated in conceptualisation, data curation, formal analysis, investigation, methodology, project administration, resources, supervision, validation, visualisation, writing the original draft and editing of drafts. KM participated in funding acquisition, conceptualisation, data curation, formal analysis, investigation, methodology, validation, review and editing of drafts. MK participated in data curation, formal analysis, investigation, methodology, validation, review and editing of drafts. RM participated in conceptualisation, data curation, formal analysis, investigation, methodology, validation, review and editing of drafts. MVD participated in conceptualisation, methodology, data curation, investigation, review and editing of drafts. KMS participated in funding acquisition, conceptualisation, data curation, formal analysis, investigation, methodology, resources, 
validation, review and editing of drafts. TN participated in conceptualisation, investigation, methodology, validation, review and editing of drafts. IG participated in funding acquisition, conceptualisation, formal analysis, methodology, resources, validation, review and editing of drafts. The SCI Guiding Principles Consensus Panel participated in funding acquisition, conceptualisation, formal analysis, validation, reviewing and editing drafts. HG participated in funding acquisition, conceptualisation, data curation, formal analysis, investigation, methodology, resources, supervision, validation, visualisation, writing the original draft, and reviewing and editing of drafts. The author(s) read and approved the final manuscript.

\section{Funding}

This research is supported in part by the IKTR Network Canadian Institutes of Health Research Foundation Grant (FDN \#143237), a Canadian Institutes of Health Research Project Grant (iKT Project grant: 156372), a Michael Smith Foundation for Health Research Scholar Award for HG (Scholar Award \#16910), and by the International Collaboration on Repair Discoveries (F1701540). KMS is supported by a Canada Research Chair in Integrated Knowledge Translation in Rehabilitation Sciences. TN holds a Postdoctoral Fellowship from the Canadian Institutes of Health Research (2016-2019). This manuscript is an amalgamation of research proposals funded by different funding bodies. None of the funding bodies had a role in writing this manuscript, or in data collection, analysis or interpretation of the data.

\section{Availability of data and materials}

Search strategies for individual databases, references of included and excluded papers, and details related to data analyses are available through Open Science Framework.

\section{Ethics approval and consent to participate} Not applicable.

\section{Consent for publication}

Not applicable.

\section{Competing interests}

The autors declare that they have no competing interests.

\begin{abstract}
Author details
${ }^{1}$ School of Health \& Exercise Sciences, University of British Columbia, Kelowna, Canada. ${ }^{2}$ International Collaboration on Repair Discoveries (ICORD), University of British Columbia, Vancouver, Canada. ${ }^{3}$ Strategic Clinical Networks ${ }^{T M}$, System Innovation and Programs, Alberta Health Services, Calgary, Alberta, Canada. ${ }^{4}$ Department of Community Health Sciences, Cumming School of Medicine, University of Calgary, Calgary, Alberta, Canada. ${ }^{5}$ Department of Community Health Sciences, Max Rady College of Medicine, University of Manitoba, Winnipeg, Manitoba, Canada. 'Library, University of British Columbia Okanagan, Kelowna, British Columbia, Canada. ${ }^{7}$ George \& Fay Yee Centre for Healthcare Innovation, University of Manitoba, Winnipeg, Manitoba, Canada. ${ }^{8}$ School of Epidemiology and Public Health, Faculty of Medicine, University of Ottawa, Ottawa, Ontario, Canada. ${ }^{9}$ CanChild Centre for Childhood Disability Research, Faculty of Health Sciences, McMaster University, Hamilton, Ontario, Canada. ${ }^{10}$ Clinical Epidemiology Program, Ottawa Hospital Research Institute, Ottawa, Ontario, Canada. ${ }^{11}$ School of Epidemiology and Public Health, University of Ottawa, Ottawa, Ontario, Canada.
\end{abstract}

Received: 10 October 2019 Accepted: 21 February 2020 Published online: 25 May 2020

\section{References}

1. Camden C, Shikako-Thomas K, Nguyen T, Graham E, Thomas A, Sprung J, Morris C, Russell DJ. Engaging stakeholders in rehabilitation research: a scoping review of strategies used in partnerships and evaluation of impacts. Disabil Rehabil. 2015;37(15):1390-400 https://doi.org/10.3109/09638288.2014. 963705.

2. Drahota A, Meza RD, Brikho B, Naaf M, Estabillo JA, Gomez ED, Vejnoska SF, Dufek S, Stahmer AC, Aarons GA. Community-academic partnerships: a systematic review of the state of the literature and recommendations for future research. Milbank Q. 2016;94(1):163-214.
3. Goodman MS, Sanders Thompson VL. The science of stakeholder engagement in research: classification, implementation, and evaluation. Transl Behav Med. 2017;7(3):486-91 https://doi.org/10.1007/s13142-0170495-z.

4. Jagosh J, Macaulay AC, Pluye P, Salsberg J, Bush PL, Henderson J, et al. Uncovering the benefits of participatory research: implications of a realist review for health research and practice. Milbank Q. 2012;90:311-46 https:// doi.org/10.1111/j.1468-0009.2012.00665.x.

5. Canadian Institute for Health Research. Strategy for Patient Oriented Research (SPOR). Ottawa; 2018. http://www.cihr-irsc.gc.ca/e/41204.html. Accessed 26 July 2019.

6. Graham ID, Tetroe JM, McLean RK. Chapter 1: some basics of integrated knowledge translation research. In: Graham ID, Tetroe JM, Pearson A, editors. Turning knowledge into action: practical guidance on how to do integrated knowledge translation research, Lippincott-Joanna Briggs Institute Synthesis Science in Healthcare Series: Book 21. Philadelphia: Lippincott Williams \& Wilkins; 2014. p. 196.

7. Graham ID, Kothari A, McCutcheon C, the Integrated Knowledge Translation Research Network Project Leads. Moving knowledge into action for more effective practice, programmes and policy: protocol for a research programme on integrated knowledge translation. Implement Sci. 2018;13:22 https://doi.org/10.1186/s13012-017-0700-y.

8. Gagliardi AR, Kothari A, Graham ID. Research agenda for integrated knowledge translation (IKT) in healthcare: what we know and do not yet know. J Epidemiol Community Health. 2017;71(2):105-6 https://doi.org/10. 1136/jech-2016-207743.

9. McKibbon KA, Lokker C, Wilczynski NL, Ciliska D, Dobbins M, Davis DA, Straus SE. A cross-sectional study of the number and frequency of terms used to refer to knowledge translation in a body of literature in 2006: a Tower of Babel? Implement Sci. 2010;5:16.

10. McKibbon KA, Lokker C, Wilczynski NL, Haynes RB, Ciliska D, Dobbins M, Davis DA, Straus SE. Search filters can find some but not all knowledge translation articles in MEDLINE: an analytic survey. J Clin Epidemiol. 2012;65: 651-9.

11. Hoekstra F, Mrklas KJ, Sibley KM, Nguyen T, Vis-Dunbar M, Neilson CJ, et al. A review protocol on research partnerships: a Coordinated Multicenter Team approach. Syst Rev. 2018;7:217 https://doi.org/10.1186/s13643-0180879-2.

12. Moher D, Moher D, Liberati A, Tetzlaff J, Altman DG. The PRISMA Group. Preferred Reporting Items for Systematic Reviews and Meta-Analyses: the PRISMA statement. PLoS Med. 2009;6(6):e1000097.

13. Pollock M, Fernandes RM, Becker LA, Featherstone R, Hartling L. What guidance is available for researchers conducting overviews of reviews of healthcare interventions? A scoping review and qualitative meta summary. Syst Rev. 2016:5(190):1-15.

14. Foster ED, Deardorff A. Open Science Framework (OSF). J Med Libr Assoc. 2017;105(2):203-6.

15. Hoekstra F, Mrklas KJ, Sibley K, Nguyen T, Vis-Dunbar M, Neilson C, Crockett L, Gainforth H, Graham ID. Understanding collaborative approaches to research: a synthesis of the research partnership literature. 2018. https://doi. org/10.17605/OSF.IO/GVR7.

16. Hoekstra F, Mrklas KJ, Nguyen T, Vis-Dunbar M, Sibley K, Gainforth HL. Review of Reviews. 2019. https://doi.org/10.17605/OSF.IO/WBFDE.

17. Bramer WM, Giustini D, de Jonge GB, Holland L, Bekhuis T. De-duplication of database search results for systematic reviews in Endnote. J Med Libr Assoc. 2016;104(3):240-3.

18. Ouzzani M, Hammady H, Fedorowicz Z, Elmagarmid A. Rayyan - a web and mobile app for systematic reviews. Syst Rev. 2016;5:210 https://doi.org/10. 1186/s13643-016-0384-4

19. Cohen J. Weighted kappa: nominal scale agreement with provision for scaled disagreement or partial credit. Psychol Bull. 1968;70(4):213-20.

20. Hsieh H-F, Shannon SE. Three approaches to qualitative content analysis. Qual Health Res. 2005;15(9):1277-88 https://doi.org/10.1177/ 1049732305276687.

21. Kung J, Chiappelli F, Cajulis OO, Avezova R, Kossan G, Chew L, et al. From systematic reviews to clinical recommendations for evidence-based health care: validation of revised assessment of multiple systematic reviews ( $R$ AMSTAR) for grading of clinical relevance. Open Dent J. 2010;4:84-91 https://doi.org/10.2174/1874210601004020084.

22. Andrews JO, Newman SD, Heath J, Williams LB, Tingen MS. Communitybased participatory research and smoking cessation interventions: a review 
of the evidence. Nurs Clin North Am. 2012;47:81-96. https://doi.org/10.1016/ j.cnur.2011.10.013.

23. Bach M, Jordan S, Hartung S, Santos-Hoevener C, Wright MT. Participatory epidemiology: the contribution of participatory research to epidemiology. Emerg Themes Epidemiol. 2017;14:2. https://doi.org/10.1186/s12982-0170056-4.

24. Blair T, Minkler M. Participatory action research with older adults: key principles in practice. Gerontologist. 2009;49:651-62 https://doi.org/10.1093/ geront/gnp049.

25. Brizay U, Golob L, Globerman J, Gogolishvili D, Bird M, Rios-Ellis B, et al. Community-academic partnerships in HIV-related research: a systematic literature review of theory and practice. J Int AIDS Soc. 2015;18:19354 https://doi.org/10.7448/IAS.18.1.19354

26. Catalani C, Minkler M. Photovoice: a review of the literature in health and public health. Health Educ Behav. 2010;37:424-51. https://doi.org/10.1177/ 1090198109342084.

27. Chen PG, Diaz N, Lucas G, Rosenthal MS. Dissemination of results in community-based participatory research. Am J Prev Med. 2010;39:372-8. https://doi.org/10.1016/j.amepre.2010.05.021.

28. Cook WK. Integrating research and action: a systematic review of community-based participatory research to address health disparities in environmental and occupational health in the United States. J Epidemiol Community Health. 2008;62:668-76. https://doi.org/10.1136/jech.2007. 067645

29. Commodore A, Wilson S, Muhammad O, Svendsen E, Pearce J. Communitybased participatory research for the study of air pollution: a review of motivations, approaches, and outcomes. Environ Monit Assess. 2017;189:378. https://doi.org/10.1007/s10661-017-6063-7.

30. Coughlin SS, Smith SA. Community-based participatory research to promote healthy diet and nutrition and prevent and control obesity among AfricanAmericans: a literature review. J Racial Ethn Health Disparities. 2017:4:25968. https://doi.org/10.1007/s40615-016-0225-0.

31. Cyril S, Smith BJ, Possamai-Inesedy A, Renzaho AMN. Exploring the role of community engagement in improving the health of disadvantaged populations: a systematic review. Glob Health Action. 2015;8:1-12. https:// doi.org/10.3402/gha.v8.29842.

32. Dempsey JS. Review of photovoice as a participatory research method to explore perceptions of adolescents with mental health concerns in using photovoice to identify perceived risk and protective factors for rural adolescent depression: Medical University of South Carolina; 2014.

33. Eyles H, Jull A, Dobson R, Firestone R, Whittaker R, Te Morenga L, Goodwin $D$, Mhurchu CN. Co-design of mHealth delivered interventions: a systematic review to assess key methods and processes. Curr Nutr Rep. 2016;5(3):160-7 https://doi.org/10.1007/s13668-016-0165-7.

34. Forsythe LP, Szydlowski V, Murad MH, Ip S, Wang Z, Elraiyah TA, et al. A systematic review of approaches for engaging patients for research on rare diseases. J Gen Intern Med. 2014;29(Suppl 3):S788-800 https://doi.org/10. 1007/s11606-014-2895-9.

35. Harrop JP, Nelson DE, Kuratani DG, Mullen PD, Paskett ED. Translating cancer prevention and control research into the community setting: workforce implications. J Cancer Educ. 2012;27:157-64 https://doi.org/10. 1007/s13187-012-0329-0.

36. Hergenrather KC, Rhodes SD, Cowan CA, Bardhoshi G, Pula S. Photovoice as community-based participatory research: a qualitative review. Am J Health Behav. 2009;33(6):686-98.

37. Hubbard G, Kidd L, Donaghy E. Involving people affected by cancer in research: a review of literature. Eur J Cancer Care. 2008;17:233-44. https:// doi.org/10.1111/j.1365-2354.2007.00842.x.

38. Jivraj J, Sacrey L-A, Newton A, Nicholas D, Zwaigenbaum L. Assessing the influence of researcher-partner involvement on the process and outcomes of participatory research in autism spectrum disorder and neurodevelopmental disorders: A scoping review. Autism. 2014;18:782-93. https://doi.org/10.1177/1362361314539858.

39. Joss N, Cooklin A, Oldenburg B. A scoping review of end user involvement in disability research. Disabil Health J. 2016;9(2):189-96. https://doi.org/10. 1016/j.dhjo.2015.10.001.

40. Krishnaswami J, Martinson M, Wakimoto P, Anglemeyer A. Communityengaged interventions on diet, activity, and weight outcomes in U.S. schools a systematic review. Am J Prev Med. 2012;43:81-91. https://doi.org/ 10.1016/j.amepre.2012.02.031
41. Lesser J, Oscós-Sánchez MA. Community-academic research partnerships with vulnerable populations. Annu Rev Nurs Res. 2007;25:317-37.

42. McVicar A, Munn-Giddings C, Seebohm P. Workplace stress interventions using participatory action research designs. Int J Workplace Health Manag. 2013;6:18-37 https://doi.org/10.1108/17538351311312303.

43. Miller J, Knott VE, Wilson C, Roder D. A review of community engagement in cancer control studies among Indigenous people of Australia, New Zealand, Canada and the USA. Eur J Cancer Care. 2012;21(3):283-95. https:// doi.org/10.1111/j.1365-2354.2012.01325.x.

44. Nitsch M, Waldherr K, Denk E, Griebler U, Marent B, Forster R. Participation by different stakeholders in participatory evaluation of health promotion: a literature review. Eval Program Plann. 2013;40:42-54. https://doi.org/10.1016/ j.evalprogplan.2013.04.006.

45. Orlowski SK, Lawn S, Venning A, Winsall M, Jones GM, Wyld K, et al. Participatory research as one piece of the puzzle: a systematic review of consumer involvement in design of technology-based youth mental health and well-being interventions. JMIR Human Factors. 2015;2:e12.

46. Portillo CJ, Waters C. Community partnerships: the cornerstone of community health research. Annu Rev Nurs Res. 2004;22:315-29.

47. Salimi Y, Shahandeh K, Malekafzali H, Loori N, Kheiltash A, Jamshidi E, et al. Is community-based participatory research (CBPR) useful? A systematic review on papers in a decade. Int J Prev Med. 2012;3:386-93.

48. Salsberg J, Parry D, Pluye P, Macridis S, Herbert CP, Macaulay AC. Successful strategies to engage research partners for translating evidence into action in community health: a critical review. J Environ Public Health. 2015;2015: 191856.

49. Snijder M, Shakeshaft A, Wagemakers A, Stephens A, Calabria B. A systematic review of studies evaluating Australian indigenous community development projects: the extent of community participation, their methodological quality and their outcomes. BMC Public Health. 2015;15: 1154 https://doi.org/10.1186/s12889-015-2514-7.

50. Brown Speights JS, Nowakowski ACH, De Leon J, Mitchell MM, Simpson I. Engaging African American women in research: an approach to eliminate health disparities in the African American community. Fam Pract. 2017;34: 322-9 https://doi.org/10.1093/fampra/cm×026.

51. Stacciarini JM. A review of community-based participatory research: a promising approach to address depression among Latinos? Issues Ment Health Nursing. 2009;30:751-7 https://doi.org/10.3109/01612840903177456.

52. Stacciarini JM, Shattell MM, Coady M, Wiens B. Review: community-based participatory research approach to address mental health in minority populations. Community Ment Health J. 2011;47(5):489-97.

53. Vaughn $L M$, Wagner $E$, Jacquez F. A review of community-based participatory research in child health. Am J Matern Child Nurs. 2013;38:4853 https://doi.org/10.1097/NMC.0b013e31826591a3.

54. Vaughn LM, Jacquez F, Lindquist-Grantz R, Parsons A, Melink K. Immigrants as research partners: a review of immigrants in community-based participatory research (CBPR). J Immigr Minor Health. 2017;19:1457-68 https://doi.org/10.1007/s10903-016-0474-3.

55. Wine O, Ambrose S, Campbell S, Villeneuve PJ, Burns KK, Vargas AO, et al. Key components of collaborative research in the context of environmental health: a scoping review. J Res Pract. 2017;13(2):R2

56. Adebayo OW, Salerno JP, Francillon V, Williams JR. A systematic review of components of community-based organisation engagement. Health Soc Care Commun. 2018;26(4):e474-84 https://doi.org/10.1111/hsc.12533.

57. Backhouse T, Kenkmann A, Lane K, Penhale B, Poland F, Killett A. Older carehome residents as collaborators or advisors in research: a systematic review. Age Aging. 2016;45:337-45 https://doi.org/10.1093/ageing/afv201.

58. Baines RL, de Bere SR. Optimizing patient and public involvement (PPI): identifying its "essential" and "desirable" principles using a systematic review and modified Delphi methodology. Health Expect. 2018;21:327-35 https:/ doi.org/10.1111/hex.12618.

59. Brear M, Hammarberg K, Fisher J. Community participation in research from resource-constrained countries: a scoping review. Health Promot Int. 2018; 18:18 https://doi.org/10.1093/heapro/dax010.

60. Bush PL, Pluye P, Loignon C, Granikov V, Wright MT, Pelletier J-F, et al. Organizational participatory research: a systematic mixed studies review exposing its extra benefits and the key factors associated with them. Implement Sci. 2017;12:119 https://doi.org/10.1186/s13012-017-0648-y.

61. Concannon TW, Fuster M, Saunders T, Patel K, Wong JB, Leslie LK, et al. A systematic review of stakeholder engagement in comparative effectiveness 
and patient-centered outcomes research. J Gen Intern Med. 2014;29:1692$701 \mathrm{https}: / /$ doi.org/10.1007/s11606-014-2878-x.

62. De Las ND, Hacker K, DiGirolamo A, Hicks LS. A systematic review of community-based participatory research to enhance clinical trials in racial and ethnic minority groups. Health Serv Res. 2012;47:1363-86 https://doi. org/10.1111/j.1475-6773.2012.01386.x.

63. Domecq JP, Prutsky G, Elraiyah T, Wang Z, Nabhan M, Shippee N, Brito JP, Boehmer K, Hasan R, Firwana B, et al. Patient engagement in research: a systematic review. BMC Health Serv Res. 2014;14:89 https://doi.org/10.1186/ 1472-6963-14-89.

64. Ehde DM, Wegener ST, Williams RM, Ephraim PL, Stevenson JE, Isenberg PJ, et al. Developing, testing, and sustaining rehabilitation interventions via participatory action research. Arch Phys Med Rehabil. 2013;94:S30-42 https://doi.org/10.1016/j.apmr.2012.10.025

65. Frankena TK, Naaldenberg J, Cardol M, Linehan C, Lantman-de Valk HS. Active involvement of people with intellectual disabilities in health research - a structured literature review. Res Dev Disabil. 2015;45-46:271-83 https:// doi.org/10.1016/j.ridd.2015.08.004.

66. Gagliardi A, Berta W, Kothari A, Boyko J, Urquhart R. Integrated knowledge translation (iKT) in health care: a scoping review. Implement Sci. 2016;11:38 https://doi.org/10.1186/s13012-016-0399-1.

67. Ganann R. Opportunities and challenges associated with engaging immigrant women in participatory action research. J Immigr Minor Health. 2013;15:341-9.

68. Greenhalgh T, Jackson C, Shaw S, Janamian T. Achieving research impact through co-creation in community-based health services: literature review and case study. Milbank Q. 2016;94:392-429 https://doi.org/10.1111/14680009.12197.

69. Manafo E, Petermann L, Vandall-Walker V, Mason-Lai P. Patient and public engagement in priority setting: A systematic rapid review of the literature. PLoS One. 2018;13 https://doi.org/10.1371/journal.pone.0193579.

70. Nilsen ES, Myrhaug HT, Johansen M, Oliver S, Oxman AD. Methods of consumer involvement in developing healthcare policy and research, clinical practice guidelines and patient information material. Cochrane Database Syst Rev. 2006:CD004563.

71. Noh H, de Sayu RP, Anderson KG, Ford CD. Community-based participatory research on issues around palliative and end-of-life care: literature review. J Hosp Palliat Nurs. 2016;18:249-55.

72. Nwanyanwu K, Grossetta Nardini HK, Shaughness G, Nunez-Smith M, Newman-Casey P-A. Systematic review of community-engaged research in ophthalmology. Expert Rev Ophthalmol. 2017;12:233-41.

73. Shen S, Doyle-Thomas KAR, Beesley L, Karmali A, Williams L, Tanel N, et al. How and why should we engage parents as co-researchers in health research? A scoping review of current practices. Health Expect. 2017;20:54354 https://doi.org/10.1111/hex.12490.

74. Smith E, Ross F, Donovan S, Manthorpe J, Brearley S, Sitzia J, Beresford P. Service user involvement in nursing, midwifery and health visiting research: a review of evidence and practice. Int J Nurs Stud. 2008;45:298-315.

75. Soh KL, Davidson PM, Leslie G, Rahman ABA. Action research studies in the intensive care setting: a systematic review. Int J Nurs Stud. 2011;48:258-68. https://doi.org/10.1016/j.ijnurstu.2010.09.014

76. Tricco AC, Zarin W, Rios P, Nincic V, Khan PA, Ghassemi M, et al. Engaging policy-makers, heath system managers, and policy analysts in the knowledge synthesis process: a scoping review. Implement Sci. 2018;13(1): 31 https://doi.org/10.1186/s13012-018-0717-x.

77. Vaughn LM, Jones JR, Booth E, Burke JG. Concept mapping methodology and community-engaged research: a perfect pairing. Eval Program Plann. 2017;60:229-37. https://doi.org/10.1016/j.evalprogplan.2016.08.013.

78. Vollm B, Foster S, Bates P, Huband N. How best to engage users of forensic services in research: literature review and recommendations. Int J Forensic Ment Health. 2017;16:183-95 https://doi.org/10.1080/14999013.2016. 1255282.

79. Adams K, Faulkhead S. This is not a guide to indigenous research partnerships. But it could help. Inf Commun Soc. 2012;15:1016-36 https:// doi.org/10.1080/1369118X.2012.709260.

80. Brett J, Staniszewska S, Mockford C, Herron-Marx S, Hughes J, Tysall C, et al. A systematic review of the impact of patient and public involvement on service users, researchers and communities. Patient. 2014;7:387-95 https:// doi.org/10.1007/s40271-014-0065-0.

81. Brett J, Staniszewska S, Mockford C, Herron-Marx S, Hughes J, Tysall C, et al. Mapping the impact of patient and public involvement on health and social care research: a systematic review. Health Expect. 2014;17:637-50 https://doi.org/10.1111/j.1369-7625.2012.00795.x

82. Carter MW, Tregear ML, Lachance CR. Community engagement in family planning in the U.S.: a systematic review. Am J Prev Med. 2015;49:S116-23.

83. Crabtree CA. A systematic review of the use of community-based participatory research in natural disaster risk reduction, A community-based participatory research approach to assist vulnerable communities in developing a disaster preparedness plan to lessen the impact of natural disasters. [Unpublished doctoral dissertation]. Manoa: University of Hawaii; 2014.

84. Dawson S, Campbell SM, Giles SJ, Morris RL, Cheraghi-Sohi S. Black and minority ethnic group involvement in health and social care research: a systematic review. Health Expect. 2018;21:3-22 https://doi.org/10.1111/hex. 12597.

85. Di Lorito C, Birt L, Poland F, Csipke E, Gove D, Diaz-Ponce A, et al. A synthesis of the evidence on peer research with potentially vulnerable adults: how this relates to dementia. Int J Geriatric Psychiatry. 2017;32:58-67 https://doi.org/10.1002/gps.4577.

86. Di Lorito C, Bosco A, Birt L, Hassiotis A. Co-research with adults with intellectual disability: a systematic review. J Appl Res Intellect Disabil. 2018; 31(5):669-86 https://doi.org/10.1111/jar.12435.

87. Haijes HA, van Thiel GJMW. Participatory methods in pediatric participatory research: a systematic review. Pediatr Res. 2016;79:676-83 https://doi.org/10. 1038/pr.2015.279.

88. Jacquez F, Vaughn LM, Wagner E. Youth as partners, participants or passive recipients: a review of children and adolescents in community-based participatory research (CBPR). Am J Community Psychol. 2013;51:176-89 https://doi.org/10.1007/s10464-012-9533-7.

89. Ragavan MI, Thomas K, Medzhitova J, Brewer N, Goodman LA, Bair-Merritt M. A systematic review of community-based research interventions for domestic violence survivors. Psychol Violence. 2019;9(2):139-55 https://doi. org/10.1037/vio0000183.

90. Strnadova I, Walmsley J. Peer-reviewed articles on inclusive research: Do coresearchers with intellectual disabilities have a voice? J Appl Res Intellect Disabil. 2018;31:132-41 https://doi.org/10.1111/jar.12378.

91. Tremblay MC, Martin DH, Macaulay AC, Pluye P. Can we build on social movement theories to develop and improve community-based participatory research? a framework synthesis review. Am J Community Psychol. 2017;59:333-62.

92. Viswanathan M, Ammerman A, Eng E, Garlehner G, Lohr KN, Griffith D, et al. Community-based participatory research: assessing the evidence. Evid Rep Technol Assess. 2004;99:1-8. https://www.ncbi.nlm.nih.gov/pubmed/154605 04.

93. Coons KD, Watson SL. Conducting research with individuals who have intellectual disabilities: ethical and practical implications for qualitative research. J Dev Disabil. 2013;19:14-24.

94. Fouché $\mathrm{CB}$, Chubb LA. Action researchers encountering ethical review: a literature synthesis on challenges and strategies. Educ Action Res. 2017; 25(1):23-34 https://doi.org/10.1080/09650792.2015.1128956.

95. Kwan C, Walsh CA. Ethical issues in conducting community-based participatory research: a narrative review of the literature. Qual Rep. 2018; 23(2):369-86.

96. Mikesell L, Bromley E, Khodyakov D. Ethical community-engaged research: a literature review. Am J Public Health. 2013;103:E7-E14 https://doi.org/10. 2105/AJPH.2013.301605.

97. Souleymanov R, Kuzmanovic D, Marshall Z, Scheim Al, Mikiki M, Worthington C, Millson MP. The ethics of community-based research with people who use drugs: results of a scoping review. BMC Med Ethics. 2016; 17. https://doi.org/10.1186/s12910-016-0108-2.

98. Tamariz L, Medina H, Taylor J, Carrasquillo O, Kobetz E, Palacio A. Are research ethics committees prepared for community-based participatory research? J Empir Res Hum Res Ethics. 2015;10:488-95. https://doi.org/10. $1177 / 1556264615615008$

99. Wilson MG, Lavis JN, Travers R, Rourke SB. Ethical challenges in communitybased participatory research: a scoping review. Qual Health Res. 2018;28(2): 189-99. https://doi.org/10.1177/1049732317690721.

100. Shippee ND, Garces JPD, Lopez GJP, Wang Z, Elraiyah TA, Nabhan M, et al. Patient and service user engagement in research: a systematic review and synthesized framework. Health Expect. 2015;18:1151-66 https://doi.org/10.1111/hex.12090.

101. Tindana P, de Vries J, Campbell M, Littler K, Seeley J, Marshall $P$, et al. Community engagement strategies for genomic studies in Africa: a review 
of the literature. BMC Med Ethics. 2015;16:24 https://doi.org/10.1186/s12910015-0014-Z.

102. Young A, Menon D, Street J, Al-Hertani W, Stafinski T. Exploring patient and family involvement in the lifecycle of an orphan drug: a scoping review. Orphaned J Rare Dis. 2017;12:188. https:/doi.org/10.1186/s13023-017-0738-6.

103. Yusuf A, Elsabbagh M. At the cross-roads of participatory research and biomarker discovery in autism: the need for empirical data. BMC Med Ethics. 2015;16:88 https://doi.org/10.1186/s12910-015-0082-0.

104. Bailey S, Boddy K, Briscoe S, Morris C. Involving disabled children and young people as partners in research: a systematic review. Child Care Health Dev. 2015;41:505-14 https://doi.org/10.1111/cch.12197.

105. Tricco AC, Lillie E, Zarin W, O'Brien K, Colquhoun H, Kastner M, Levac D, Ng C, Pearson Sharpe J, Wilson K, Kenny M, Warren R, Wilson C, Stelfox HT, Straus SE. A scoping review on the conduct and reporting of scoping reviews. BMC Med Res Methodol. 2016;16:15 https://doi.org/10.1186/s12874016-0116-4.

106. INVOLVE. What is public involvement in research? INVOLVE; 2019. https:// www.invo.org.uk/find-out-more/what-is-public-involvement-in-research-2/. Accessed 26 July 2019.

107. IAP2 Spectrum of Public Participation. 2018. https://cdn.ymaws.com/www. iap2.org/resource/resmgr/pillars/Spectrum_8.5x11_Print.pdf. Accessed 16 Apr 2019.

108. Hanley B, Bradburn J, Barnes M, Evans C, Goodare H, Kelson M, et al. Involving the public in NHS, public health and social care research: briefing notes for researchers. 2nd ed; 2003.

109. Hamilton CB, Leese JC, Hoens AM, Li LC. Framework for advancing the reporting of patient engagement in rheumatology research projects. Curr Rheumatol Rep. 2017;19(7):38 https://doi.org/10.1007/s11926-017-0666-4.

110. Michie S, Richardson M, Johnston M, Abraham C, Francis J, Hardeman W, et al. The behavior change technique taxonomy (v1) of 93 hierarchically clustered techniques: building an international consensus for the reporting of behavior change interventions. Ann Behav Med. 2013;46(1):81-95 https:// doi.org/10.1007/s12160-013-9486-6.

111. Hoffmann TC, Glasziou PP, Boutron I, Milne R, Perera R, Moher D, et al. Better reporting of interventions: template for intervention description and replication (TIDieR) checklist and guide. BMJ. 2014;348:g1687 https://doi.org/ 10.1136/bmj.g1687.

112. Pawson R, Greenhalgh T, Harvey G, Walshe K. Realist review--a new method of systematic review designed for complex policy interventions. J Health Serv Res Policy. 2005;10(Suppl 1):21-34 https://doi.org/10.1258/ 1355819054308530.

113. Rycroft-Malone J, McCormack B, Hutchinson AM, DeCorby K, Bucknall TK, Kent $B$, et al. Realist synthesis: illustrating the method for implementation research. Implement Sci. 2012;7:33 https://doi.org/10.1186/1748-5908-7-33.

114. Oliver K, Kothari A, Mays N. The dark side of coproduction: do the costs outweigh the benefits for health research? Health Res Policy Syst. 2019;17: 33 https://doi.org/10.1186/s12961-019-0432-3.

115. Israel BA, Schulz AJ, Parker EA, Becker AB. Review of community-based research: Assessing partnership approaches to improve public heath. Annu Rev Public Health. 1998;19:173-202.

116. Jull J, Giles A, Graham ID. Community-based participatory research and integrated knowledge translation: advancing the co-creation of knowledge. Implement Sci. 2017;12:150

117. Vis-Dunbar M, Hoekstra F, Mrklas KJ, Sibley K, Nguyen T, Neilson C, Gainforth HL. Partnership search strategy. 2020. https://doi.org/10.17605/OSF.IO/ KWBU4.

118. Pare G, Trudel MC, Jaana M, Kitsiou S. Synthesizing information systems knowledge: a typology of literature reviews. Inf Manag. 2015;52(2):183-99 https://doi.org/10.1016/j.im.2014.08.008.

119. Nguyen T, Graham ID, Mrklas KJ, et al. How does integrated knowledge translation (IKT) compare to other collaborative research approaches to generating and translating knowledge? Learning from experts in the field. Health Res Policy Sys. 2020;18:35. https://doi.org/10.1186/s12961-020-0539-6.

\section{Publisher's Note}

Springer Nature remains neutral with regard to jurisdictional claims in published maps and institutional affiliations.

\section{Ready to submit your research? Choose BMC and benefit from}

- fast, convenient online submission

- thorough peer review by experienced researchers in your field

- rapid publication on acceptance

- support for research data, including large and complex data types

- gold Open Access which fosters wider collaboration and increased citations

- maximum visibility for your research: over $100 \mathrm{M}$ website views per year

At BMC, research is always in progress.

Learn more biomedcentral.com/submissions 